\title{
Acceleration Due to Gravity at the National Bureau of Standards*
}

\author{
D. R. Tate \\ Institute for Basic Standards, National Bureau of Standards, Washington D.C. 20234 \\ (September 26, 1967)

\begin{abstract}
A determination of the absolute value of the acceleration due to gravity was completed in June 1965 at the National Bureau of Standards near Gaithersburg, Maryland. The determination resulted in a value of 980.1018 centimeters per second squared for a reference point on the first floor of the Engineering Mechanics Building. The result was published in The Journal of Research of the National Bureau of Standards, Vol. 70C, No. 2, Engineering and Instrumentation, page 149, April-June 1966. The present paper describes in detail the apparatus and the techniques employed and presents the summarized data from which the value was derived.
\end{abstract}

Key Words: Absolute gravity, acceleration, free-fall, g, gravity, Potsdam.

\section{Introduction}

\subsection{Absolute Gravity as the Standard of Force}

Determinations of the acceleration due to the gravitational attraction of the earth have been made many times since the early observations of Galileo. Up to the end of the nineteenth century measurements were made with the primary purpose of gaining knowledge about the figure of the earth and the effects of the distribution of mass near its surface. In the years that have followed, gravity values have not only continued to be of great interest to the geodesist but also have fulfilled an additional role in supplying the base for the standard of force. Virtually every measurement which involves force, such as electrical current or pressure, depends in some manner on knowledge of the gravitational field of the earth.

It is generally agreed that the unit of force is defined by the second Newtonian law of motion and the primary standards of length, mass, and time. The determination of the acceleration due to gravity links the dynamic relationship of the Newtonian law to a permanent reference in the gravitational field of the earth. The gravitational field strength, multiplied by an accurately determined mass value, then becomes the working standard of force. From this point onward the normal process by which a measurement system is established, i.e., by the comparison of like quantities, can successfully include force as an element.

An essential part of the process, of course, is a means of extending the single point value of the field intensity to other points as needed. This extension is

\footnotetext{
*This paper will be available as NBS Monograph 107 from the Superintendent of Docu-
} ments, Government Printing Office, Washington, D.C. 20402. Price 25 cents. accomplished through the use of comparators such as geodetic pendulums and gravity meters. The results comprise a unified network which will eventually cover the habitable portions of the earth.

The relationship between the acceleration due to gravity and the concept of the gravitational field is so direct that it is frequently ignored in practical applications. However, distinction between the two concepts is essential to a logical understanding of the basic equations of mechanics.

Consider a body of mass $m$ at rest in the gravitational field of the earth. The body experiences a force which can be expressed as

$$
\mathbf{F}=-m \nabla \varphi ;
$$

$\varphi$ is the potential, a function of position in space relative to a coordinate system at rest with respect to the earth. If now the body is free to move, it will experience an acceleration, $g$, such that

$$
\mathbf{F}=k m \mathbf{g} \text {. }
$$

Thus, with the assumption that $m$ is the same quantity in both cases,

$$
\nabla \varphi ;=-k g \text {. }
$$

The strength of the gravitational field is, therefore, equal to the acceleration due to gravity multiplied by a numerical factor, $k$, which depends only upon the system of units of measurement selected. In any coherent system, $k$ is equal to unity.

Although the validity of the assumption above, that the inertial mass is equal to the gravitational mass, 
has frequently been questioned, experiments such as those with the Eötvös pendulum [1] ${ }^{1}$ indicate that any effects must be less than one part in $10^{11}$. This amount is several orders of magnitude less than the sensitivity of any absolute measurement now under consideration.

\subsection{Previous Determinations}

The history of absolute gravity experiments published within the past 70 years has been reviewed by several authorities. Cook [2], in particular, gives a very thorough treatment. Briefly summarized, an absolute determination published in Potsdam, Germany, in 1906 by Kühnen and Furtwängler [3] became the base for the world network of relative gravity observations. Two later determinations, one by Feyl and Cook [4] at Washington, D.C. and the other by Clark [5] at Teddington, England, disagreed with the Potsdam result by significant amounts. Reexamination of the Potsdam result by Dryden [6] and of Clark's and Heyl's results by Jeffreys [7] improved the agreement but did not fully resolve the questions raised.

In 1956 the results of three new determinations by Agaletskii and Egorov [8] and Martsiniak [9] tended to support the conclusion that the original Potsdam result is too high by some ten to twenty parts per million. Three other absolute determinations appeared within the next few years, Preston-Thomas et al. [10], Thulin [11], and Faller [12]; all have shown reasonably good agreement with each other and have ranged from about 12.7 to 14.5 milligals ${ }^{2}$ ( $\mathrm{mGal}$ ) below the Potsdam result. More recently Cook [13] has reported the result of a determination at the National Physical Laboratory differing from the Potsdam result by approximately $13.7 \mathrm{mGal}$.

\subsection{Accuracy and Precision}

The requirements for accuracy in absolute gravity measurements are much the same for the geodesist and the metrologist. An accuracy of one part in a million is critically needed and an accuracy of one or two parts in ten million would be most desirable. It has been suggested that some form of absolute gravity apparatus which can readily be transported and set up in different sites might resolve the apparent bias between some measurements with geodetic pendulums. If such an approach is to be effective, a demonstrated stability in the portable absolute apparatus of one part in ten million is quite essential.

The results of absolute determinations in which measurements of several non-related parameters are combined to obtain an estimate of the magnitude of a presumed constant quantity, the true value of which is unknown, cannot realistically be assigned a level of accuracy. One can and does derive an index, such as the standard deviation, of the precision of individual determinations made over a short period of time. From this index an estimate may be derived of the precision which might be expected for the means of similar sized

\footnotetext{
' Figures in brackets indicate the literature references at the end of this paper.

${ }^{2} \mathrm{~A}$ milligal is a geodetic unit of gravity equal to $10^{-3} \mathrm{~cm} / \mathrm{s}^{2}$, approximately $1 \mathrm{ppm}$ of the value of $g$.
}

groups of measurements drawn from the same source. If such groups of measurements are actually made, separated by periods of a day or more, the standard deviations of the individual measurements may be much the same but the means of the groups will often show more scatter than would have been predicted from the internal consistency of any of the groups. The conclusion is that the composition of the population from which the samples have been drawn has changed with time. It is inferred that there must exist sources of bias which vary from day to day but which do not change appreciably over the course of a single set of measurements.

The nature and extent of variability of this bias usually remain unknown. The demonstrated presence of bias, of course, arouses the investigator to try to analyse it by looking for correlation with other parameters. In general, though, this process has already been carried out to the limits of practicality. This residuum of bias is probably a major cause of the wellknown tendency of the scientist to continue his measurements indefinitely.

In a broad sense, therefore, one can consider that an estimate of the accuracy of an experimental measurement can be made only when the resultant value can be compared to a defined or assumed true norm. In the absence of such a true norm, a determination obtained from a series of measurements made with a single piece of apparatus must be regarded as only a sample from an unknown population. Estimates of the precision should be made, together with statements of the sensitivity to variations in the component measurements in relation to the precision with which those standards were established. Such statements give limits to the error only from known sources. The final appraisal of the limits of knowledge about the true value of the constant determined must come from the results of a group of completely independent experiments differing in method, location, and in the personnel conducting them.

\subsection{Methods for Gravity Determinations}

Taken without regard for experimental difficulty, it would appear that the most direct method for determining the absolute value of the acceleration due to gravity would be to observe the motion of some object moving without constraint under the action of the gravitational field of the earth. Up to about 1950 the use of such a method was impracticable because of the difficulty in measuring the short lengths of time involved. Virtually all gravity measurements were made with some form of pendulum.

Basically the pendulum method substitutes a system with a maximum of constraint for a system with a minimum of constraint. From a purely practical viewpoint the pendulum method offers many advantages. An uncertainty of one part in a million in the measurement of the pendulum length produces the same relative uncertainty in the determination of $g$. An uncertainty of one part in a million in the measurement of time results in an uncertainty of two parts in a million in $g$, but the length of the time interval can be 
increased to the point where timing errors become negligible. The difficulties of the pendulum method lie in the complex theoretical corrections for pendulum flexure and the uncertainties contributed by motion of the pendulum support and by the indefinite point of rotation at the knife edge.

Experiments involving unconstrained motion under gravitational forces have, with the perfection of frequency counting electronic circuitry, developed in many diverse forms. The most elementary form of such an experiment would be one in which an object is released from rest and allowed to fall a known distance in a vacuum. If time is measured from the instant of release to the point where the object has travelled the measured distance, the acceleration may be computed from the simple relationship

$$
g=\frac{2 d}{t^{2}}
$$

Here the sensitivity in the determination of $g$ is the same as in the case of the pendulum and the efficiency of measurement would be high. Unfortunately the experimental difficulties in the measurement of time and length and in the release of the object are so formidable that no investigator up to the present has undertaken such an experiment.

The restrictions of the elementary free-motion experiment can be eliminated by releasing the object prior to the start of the time measurement. In this case the object acquires an initial velocity of unknown magnitude which can be successfully eliminated by the addition of one or more distances over which time is measured. A parallel and equally effective approach is to measure the distance the object travels during two or more known intervals of time.

These techniques, while successfully eliminating the experimental difficulties of the elementary experiment, are introduced at the cost of an increase in sensitivity to errors in the measurement of length and time. The method offers many advantages from the experimental viewpoint and has been employed in one form or another by several investigators.

In 1947 [14], M. Charles Volet, then Director of the Bureau International des Poids et Mesures, suggested that if an object were projected upwards, passing two position sensing stations separated by a known distance and then allowed to fall back, and the time between successive passages at each level recorded, a considerable increase in measurement efficiency would be obtained. The method is indeed a most effective one since the sensitivity to length errors is the same as for the elementary experiment and the sensitivity to timing errors is very nearly equal to that in an elementary experiment with four times the height of fall. The principal disadvantage is the increased difficulty in the experimental technique required. The method is currently being employed in experiments at the National Physical Laboratory by Cook [2], and at the Bureau International des Poids et Mesures by Sakuma [15]. Sakuma's method embodies the concept of making the moving object one reflector of an interferometer system illuminated by a gas laser light source. This approach has the great advantage of making the length and time measurements occur simultaneously and avoids the limitations of an intermediate length standard. Faller's experiment [12] was the first published determination using the falling interferometer plate principle. He was limited to a very short length of drop by the necessity of using a conventional light source.

\section{The NBS Determination}

\subsection{General Description}

Following a review and appraisal of several possible approaches to absolute gravity measurements, it was decided to employ a modification of the direct free-fall method with the release of the object preceding the timing sequence. The method makes use of a concept introduced by Agaletskii and Egorov [8] in which the released object falls within a chamber which is itself falling. Agaletskii's technique was to determine the acceleration of the object with respect to the chamber and, separately, to determine the acceleration of the chamber with respect to the earth. The measurements were made by a multiple flash method at constant frequency.

In the experiment at the National Bureau of Standards the acceleration of the inner falling object was determined directly with respect to the earth from measurements of the time required for two intervals of length on a fused silica tube to pass an optical sensing station.

The apparatus for the experiment was first set up at the National Bureau of Standards in Washington, D.C., in 1961 in a pair of small rooms known as the sub-subbasement of the East Building. This had been the site of the absolute determination by Heyl and Cook [4]. In February of 1964 the apparatus was damaged in a flood which left the site in a nearly unusable condition. The apparatus was reconstructed in the summer of the same year and installed in room 129 of the Engineering Mechanics Building (Building 202) at the new site of the Bureau near Gaithersburg, Maryland. The measurements leading to the final value were taken during April, May, and June of 1965.

In the experiment a fused silica tube slightly more than a meter in length rested on a seat in a vacuum chamber a few centimeters longer than the tube. The vacuum chamber was mounted on a carriage and held by a latch at the top of a pair of vertical guide rods secured in a rigid frame. The arrangement was such that when the latch was released, the carriage was free to descend vertically down the guide rods under the influence of gravity. A schematic diagram of the apparatus is shown in figure 1. Friction between carriage and guide rods was reduced to a low level by antifriction bearings. In the latched position the carriage was under an additional downward force provided by an adjustable, short-travel, spring-loaded plunger. When the latch was released the carriage moved downward with an acceleration about ten per- 


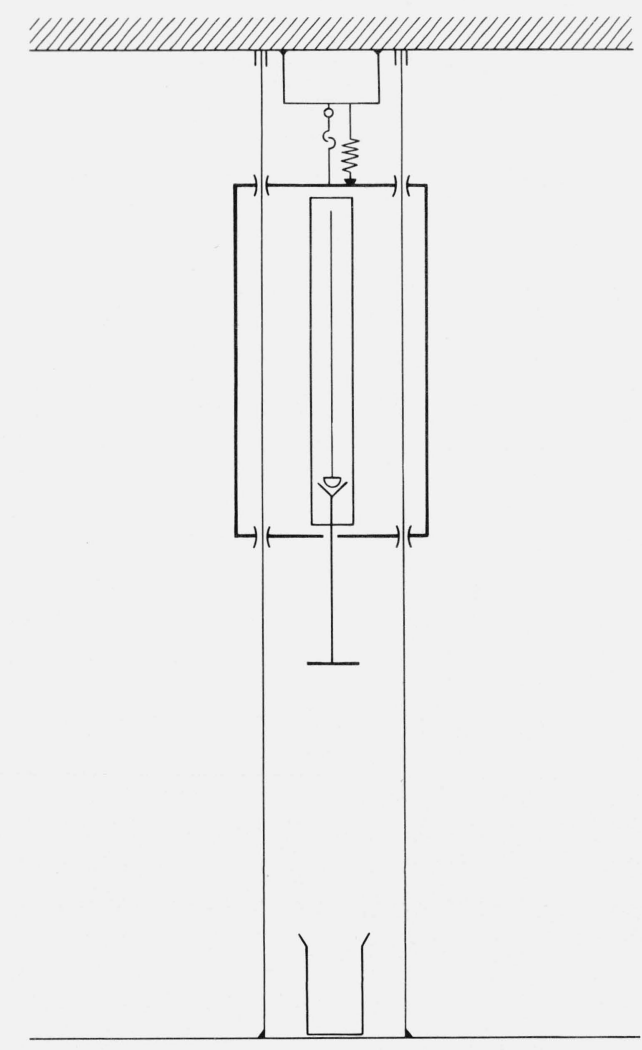

FIGURE 1. Schematic view of gravity apparatus.

cent greater than the acceleration due to gravity for the first $8 \mathrm{~mm}$ of its travel. The additional acceleration of the car effectively separated the fused silica tube from its seat inside the chamber, leaving the tube floating without contact with the chamber for the duration of the fall of the carriage. By proper adjustment of the spring plunger travel, the relative displacement between the silica tube and the chamber could be restricted to a millimeter or so after the initial separation. After a fall of about $1 \frac{1 / 4}{m}$ the carriage was brought to a smooth stop by an air dash-pot.

Only the force due to gravity acted upon the silica tube inside the chamber. The tube, which was opaque, carried three transparent slits, to be described later. The slits defined two lengths, one extending from the slit near the lower terminus of the tube to the second slit $30 \mathrm{~cm}$ above it, and the other extending from the lower slit to the third slit $100 \mathrm{~cm}$ above it. The vacuum chamber was provided with pairs of ports at locations opposite the slits. A single position-sensing station consisted of a light source, a long focus microscope, and a photomultiplier cell. As each slit passed the station, an illuminated image of it was projected on a plane containing a stationary slit within the microscope tube. Beyond this reference slit was the photomultiplier cell. The reference slit was dark until the bright image of a moving slit swept across it, causing the photomultiplier cell output to rise from nearly zero to full anode potential. A two-channel electronic timer system was triggered at some predetermined potential level near the midpoint of the linearly rising photocell output curve.

During the fall of the tube, both timer channels were started by the passage of the lower slit past the position-sensing station. One channel was stopped by the passage of the second slit and the other channel was stopped by the passage of the third slit. They thus registered the transit time for the $30-\mathrm{cm}$ and $100-\mathrm{cm}$ lengths, respectively.

The apparatus was arranged so that the fused silica tube fell a distance of $6.8 \mathrm{~cm}$ before the first slit initiated the timing sequence. Thus about $118 \mathrm{~ms}$ elapsed between the release of the latch and the start of the time measurements.

The lengths corresponding to the two distances on the fused silica tubes were measured, using the same apparatus employed for the free fall time measurements. The fused silica rod was secured firmly in its seat and a measurement made of the distance the carriage moved between the locations where the timers would have been triggered by the photocell signals. The technique for the length measurements is described in another part of this paper. The method has the advantage of including effects of the vacuum on the actual length of the rod as well as any optical effects from the ports in the vacuum chamber walls. More importantly, it is a direct measurement of the quantity desired.

The following summary indicates the magnitudes of the parameters measured and the sensitivity of the result in terms of the least count in the measurements.

Magnitudes of measured parameters

Short length

Long length

Time for short length

Time for long length

30 centimeters

100 centimeters

156 milliseconds

348 milliseconds

Least count in measuring instruments

Length
Time
Temperature

0.1 micrometer

0.1 microsecond

0.02 degree Celsius

Sensitivity of the value of $g$ to variations equal to the least count
Short length

Long length

Time for short length

Time for long length

Temperature of silica tube

Temperature of invar standard
0.7 milligal

0.3 milligal

1.8 milligal

1.4 milligal

0.01 milligal

0.02 milligal

\subsection{The Falling Objects}

Four tubes were employed in the experiment, all constructed to the same nominal dimensions from 
clear, fused silica tubing having an outside diameter of $15 \mathrm{~mm}$, and a wall thickness of $1 \mathrm{~mm}$. Each tube had a length of $107 \mathrm{~cm}$. A metal sleeve with an outside diameter of $19 \mathrm{~mm}$ fitted over one end of each tube and was cemented in place with epoxy cement. The external end of the sleeve was machined to a spherical radius of $12 \mathrm{~mm}$. The sleeve formed the lower support tip for the silica tube.

At a point about $11 \mathrm{~cm}$ from the other end of the silica tube a second sleeve was attached, fitted with guide pins for alinement and rotation in the vacuum chamber. Figure 2 shows a schematic view of an assembled tube.

Each silica tube was fitted with three rectangular clear apertures formed by pairs of bevel-edge metal plates cemented to the outer surface of the tube wall. The plate edges were perpendicular to the longitudinal axis of the tube and spaced so that the aperture took the form of a transverse slit about $1 \mathrm{~mm}$ wide and 7 $\mathrm{mm}$ long. In the experiment the dimensions of the slit were of no particular consequence, as the timing sequences were generated by the transition from dark to light as the lower edges of the slits passed the optical axis of the position sensing optical system. The upper slit boundary was supplied to provide a sharp cut-off of the light beam in order to prevent spurious triggering of the timers by photo-tube noise in a slowly decaying light pattern.

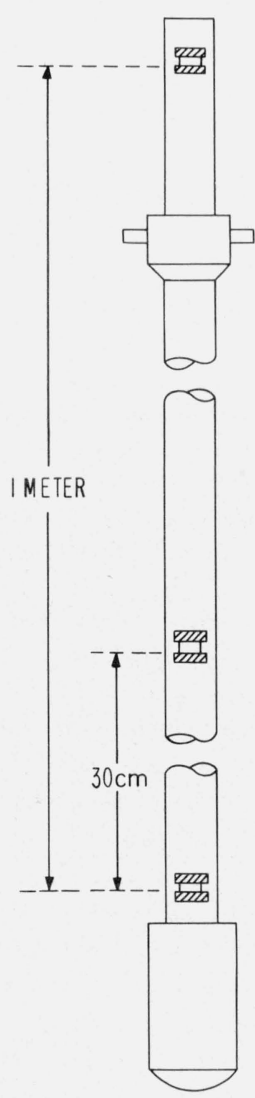

FIGURE 2. Free-fall object showing slits and guide sleeves.
The experiment required that the critical edges of all three slits be mutually parallel, coplanar, and perpendicular to the axis of the fused silica tube. To this end, a special jig was made to hold the silica tube and aperture edges during the operation of cementing the edges to the tube.

The jig consisted of a channel-shaped frame of steel having two vee-blocks attached on the centerline of the channel web at positions corresponding to the lower support tip and the upper guide sleeve of the silica tube. Three pairs of rectangular notches were machined into the flange-edges of the channel at locations corresponding to the $0-, 30-\mathrm{cm}$, and $1-\mathrm{m}$ aperture locations on the silica tube. The parallelism of the jig notches was checked with an autocollimator and the notches hand-finished to be parallel within $7 \mathrm{~s}$ of arc. This amount corresponds to an error of $0.03 \mu \mathrm{m}$ in $1 \mathrm{~mm}$.

In using the jig, cut and finished aperture edges were attached to special holders. These were flat bars which could be set into the jig notches and secured in place with hold-down screws to maintain alinement during the setting of the cement. The holders were constructed with flats lapped on the leading edges at the points where they contacted the forward edges of the jig notches. The center portion of the holder edges was relieved. An aperture edge was attached to each of three such holders by metal fingers which gripped the aperture plates at the sides, the defining edges of the aperture plates being made coplanar with the lapped flats on the holders by a light lapping operation. The finished assemblies were then checked in a comparator.

A silica tube, complete with supporting tip and guide sleeve, was clamped in the vee-blocks which had been shimmed to provide a clearance of about $0.07 \mathrm{~mm}$ between the surface of the silica tube and the under face of the aperture plate and holder assemblies. A dot of epoxy cement was then placed on the center of each aperture plate mounted in its holder. The three holders were inverted and each carefully placed in a jig notch and secured in place with the lapped edges forced against the leading edge of each notch.

After the cement had set for $24 \mathrm{hr}$, the gripping fingers coupling the holders to the aperture edges were released and the holders removed from the jig. The bond between the silica rod and the aperture plates was then reinforced with additional cement. Three opposing aperture plates to complete the framing of the apertures were then installed by a similar technique. The bond formed between the metal aperture edge plates and the silica tube by the epoxy cement was quite strong. Even the bond formed by the initial small dot of cement had sufficient strength after 3 or 4 days to require considerable force to separate the two parts.

As a final step each silica tube was given several coats of silver conductive paint to prevent the formation of localized electrostatic charges. Preliminary experiments with silica rods or tubes in vacuum had shown that under certain conditions a substantial electrostatic charge was generated by the separation 
of the supporting tip of the tube from the seat in the vacuum chamber. Even though the falling object was surrounded by the grounded metal vacuum chamber, the internal field was not necessarily zero and the silica tube tended to be drawn out of the true vertical line as it fell. In some cases the effect was so severe as to cause the timers to malfunction. The conductive paint, which reduced the surface resistance of the silica tube of less than $10 \Omega$, eliminated this difficulty. Only the clear apertures and corresponding areas on the opposite face of the tube were not coated.

\subsection{The Vacuum Chamber}

The vacuum chamber was fabricated in three sections joined by flanges with O-ring seals. It was constructed of brass tubing having an outside diameter of $4.76 \mathrm{~cm}$ and a wall thickness of $0.32 \mathrm{~cm}$. The outside of the chamber was covered by two layers of 3-mm cork sheet and finally by a layer of heavy aluminum foil to reduce the effects of ambient temperature fluctuations. The vacuum chamber assembled on the carriage of the machine is shown in figure 3 .

The lower section of the chamber contained the support cone for the silica tube, the vacuum gage, the vacuum pump connection, and the optical windows for the zero and $30 \mathrm{~cm}$ apertures of the silica tube. The middle section of the vacuum chamber housed the upper guide bearing for positioning the silica

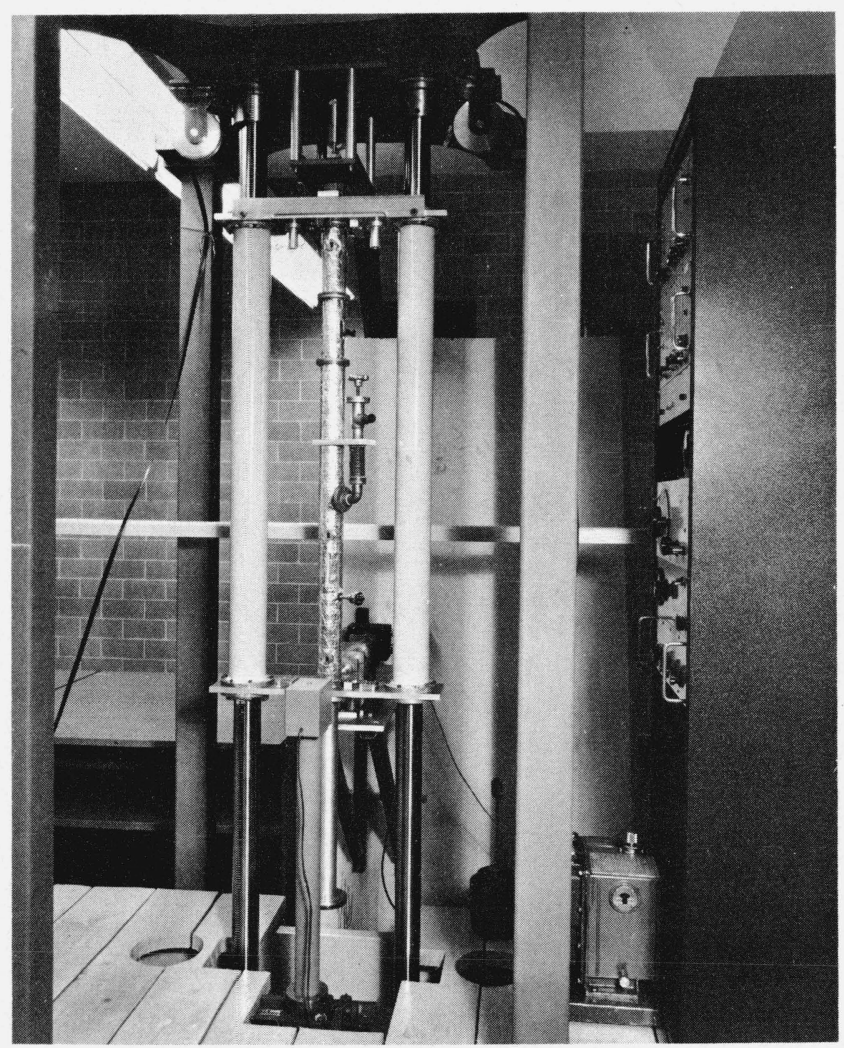

FIGURE 3. Upper portion of gravity machine showing guide rods, carriage, and vacuum chamber. tube preparatory to release. In the upper section of the vacuum chamber were the optical windows for the $1-m$ aperture of the silica tube.

The vacuum chamber was so arranged that it was necessary to disassemble only the upper section in order to remove or insert a silica tube.

The support cone formed an integral part of the removable base closure for the lower section of the vacuum chamber. It was made by machining a base with a recess in the form of a $90^{\circ}$ vertex angle cone. The major portion of the cup formed in this way was then milled out, leaving only three ribs, $120^{\circ}$ apart and about $7 \mathrm{~mm}$ wide. The shape was a compromise between the desirable 3-point support and a full cone seat. It was considered that a 3-point support would tend to produce localized deformations of the silica tube support tip which would in time make the contact unstable. Earlier experiments with a support seat which more nearly approximated a full cone had likewise resulted in some undesirable characteristics.

The upper guide bearing mechanism was built as a unit into the middle section of the vacuum chamber. It consisted of two end flange plates with O-ring seals each connected by a metal bellows to a central sliding unit. A section of brass tubing of the same dimensions as the other sections of the vacuum chamber was attached between the end flange plates providing structural support and also guidance for the central sliding unit. The central sliding unit terminated in a tube having an inside diameter of $19 \mathrm{~mm}$ which projected above the end flange plate into the upper portion of the vacuum chamber. To this tube was attached a bushing having an inside diameter just slightly larger than the upper sleeve of the silica tube. The upper surface of the bushing was a double-vee cam surface to engage the guide pins of the silica tube sleeve as shown in figure 4 .

When a silica tube is installed in the assembled vacuum chamber, the arrangement is such that when the central sliding unit is moved to the upper limit of its travel, the silica tube is picked up by the guide pins in the vee-shaped notches and rotated into the proper orientation with respect to the optical axis of the position sensing station. Then, as the central sliding unit is lowered, the silica tube is seated in the support cone at the bottom of the vacuum chamber but is precisely alined by the guide bushing surrounding the sleeve on the silica tube. When the central sliding unit reaches the lower limit of travel where it can be locked in place, the guide bushing is completely disengaged from the silica tube sleeve and the silica tube stands supported only by the support cone. It is then ready for a free-fall measurement.

During length measurements on the silica tube the central sliding unit was left in the center of its travel where the silica tube received lateral guidance from the bushing but rested on the support cone.

The six optical windows in the vacuum chamber were Pyrex glass discs, $4.5 \mathrm{~mm}$ thick and $19 \mathrm{~mm}$ in diameter. They were optically polished to be flat within one-half wave length of the green mercury line. The discs were inserted in machined wells in the cham- 


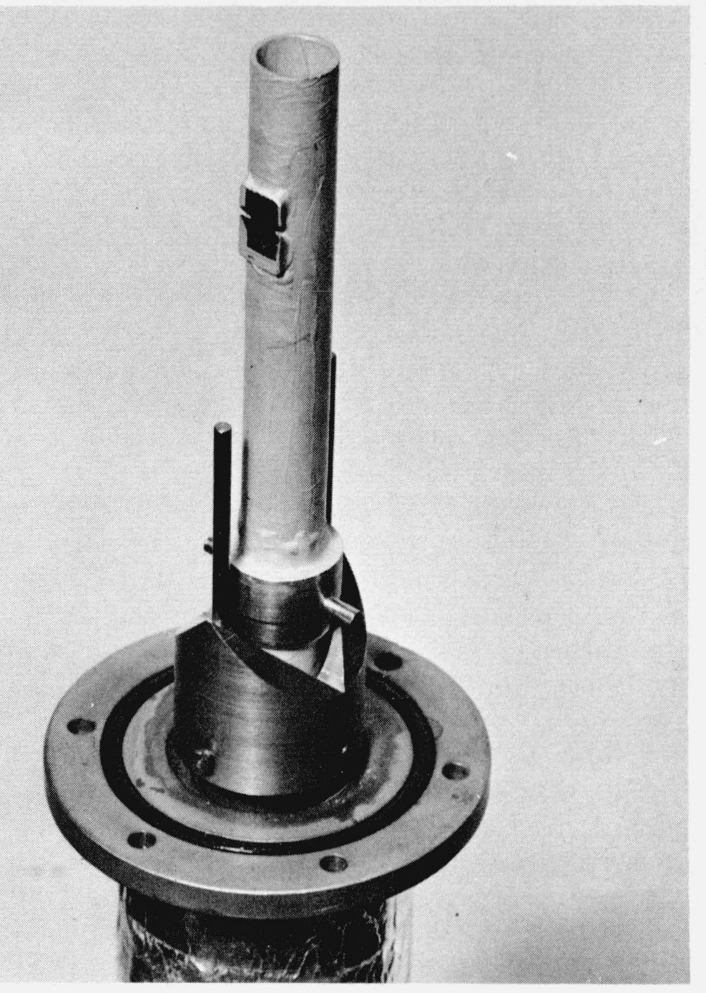

FIGURE 4. Vacuum chamber with upper section removed, showing fused silica tube and alignment mechanism.

ber wall on O-ring seals. The clear apertures were reduced to areas about $13 \mathrm{~mm}$ high by $8 \mathrm{~mm}$ wide by masks.

The vacuum connections to the vacuum chamber were made through a special flange and O-ring seal near the midheight of the chamber. A copper tube connected to the flange led to a $19-\mathrm{mm}$ valve supported by the chamber. A detachable connection from the valve permitted coupling the system to a mechanical pump by a flexible hose. The system was designed to present a minimum throat diameter of $19 \mathrm{~mm}$. The vacuum pump was a two-stage mechanical pump with a free air capacity of 140 liters per min.

The vacuum chamber was equipped with a thermocouple-type vacuum gage inserted in the chamber wall at a point about $24 \mathrm{~cm}$ below the connection to the vacuum pump. Once the vacuum chamber had been outgassed it was possible to attain a pressure of about $0.13 \mathrm{~N} / \mathrm{m}^{2}$ (1 $\mu \mathrm{m}$ of mercury). The vacuum pump was operated continuously except during the length or free-fall measurements. Generally the leakage rate for the system ranged from about 0.4 to $0.6 \mathrm{~N} / \mathrm{m}^{2} / \mathrm{hr}$ at this pressure.

A mercury-in-glass thermometer was imbedded in the thermal insulation of the vacuum chamber near the vacuum gage. The thermometer bulb was kept in thermal contact with the brass wall of the chamber by a pad of compacted aluminum foil. The thermometer was covered by the cork insulation except for a slit exposing a portion of the engraved scale. The ther- mometer scale was graduated to $0.2 \mathrm{deg}$ Celsius and read by estimation to $0.02 \mathrm{deg}$. This thermometer was identical to the thermometers used to measure the temperature of the length standard.

\subsection{Mechanical Design}

The frame of the apparatus for the determination of the acceleration due to gravity consisted of a base plate of steel $120 \mathrm{~cm}$ square and $3.8 \mathrm{~cm}$ thick, grouted to the floor of the building and held down by four $2.5-\mathrm{cm}$ anchor bolts. At each corner of the plate there was a hollow square-section steel column $3.7 \mathrm{~m}$ high. Bridging the tops of the columns was a plate of steel $120 \mathrm{~cm}$ on each side and $5 \mathrm{~cm}$ thick, cut out along the edges to reduce the weight. Two guide rods for the carriage were supported in the frame gripped in rings bolted to the base and upper plates. The internal diameter of each ring was $7.5 \mathrm{~cm}$; each ring had four centering screws. The guide rods were $6.35 \mathrm{~cm}$ in diam with a tolerance of $0.1 \mathrm{~mm}$. They were selected to be straight to within $0.08 \mathrm{~mm}$ per $\mathrm{m}$ of length. The spacing between the guide rods was nominally $40 \mathrm{~cm}$.

The carriage of the apparatus was about $117 \mathrm{~cm}$ long and was formed of two aluminum alloy plates separated by vertical tubes of aluminum alloy as shown in figure 3 . The two guide rods passed through holes in the carriage plates and through the interior of the two aluminum alloy tubes.

At both ends of one tube two pairs of ball bearings were mounted so as to center the steel guide rod within the aluminum alloy tube. A single pair of ball bearings at the upper end of the opposite tube constrained the carriage against rotation about the opposite guide rod. The arrangement of the ball bearing guides is shown in figure 5 . The five pairs of ball bearings were adjusted against the guide rod with a slight negative clearance to eliminate any possible

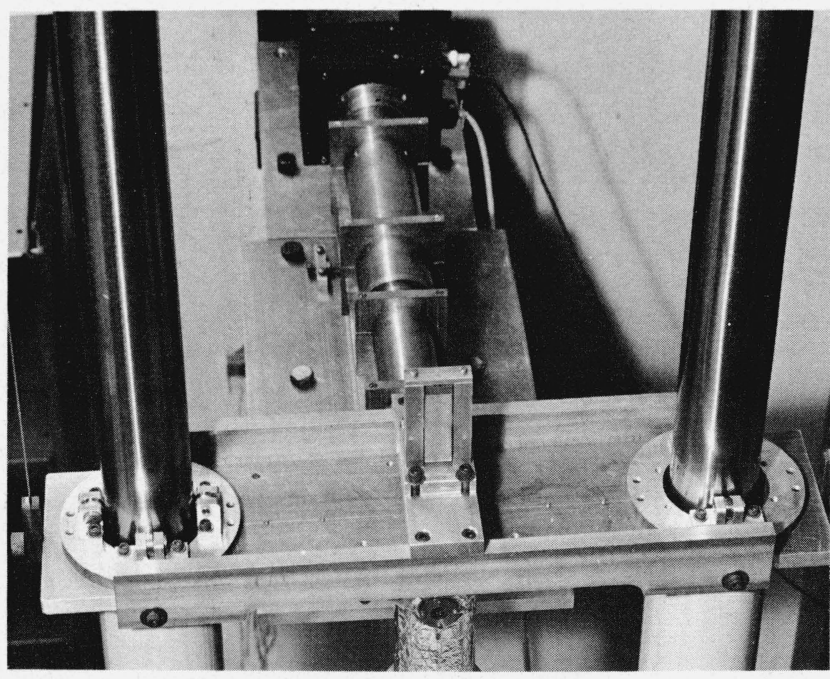

FigURE 5. Upper end of carriage showing guide bearings and latch connection. 
lateral freedom of motion. The motion of the carriage was found to be extremely linear and yet with only about $100 \mathrm{~g}$ friction in the direction of free fall.

Since it was necessary to counterbalance the weight of the carriage and vacuum chamber about $22 \mathrm{~kg}$ during length measurements, a pair of ball bearing pulley wheels were attached to the upper main frame plate near the vertical extension of the ends of the carriage frame. Weight hangers were connected to two spring steel ribbons $12.7 \mathrm{~mm}$ by $0.18 \mathrm{~mm}$ which passed over the pulleys and terminated in fittings that could be coupled to the frame of the carriage.

A view of the assembled frame, carriage and vacuum chamber is shown in figure 6 . The wood platform for the observer was supported from the building floor and did not touch the gravity apparatus.

The main guide rods were alined parallel to the direction of gravity by the following procedure. Near each guide rod a fine wire was suspended from the upper plate of the frame. A mass of sufficient weight to stress the wire moderately was attached to the lower end of the wire. The lower end of the wire and the mass were immersed in a pot of oil to damp out oscillations. A microscope with reticule graduated to $0.01 \mathrm{~mm}$ was mounted on the counterbalanced carriage and focussed on the wire, first in a plane perpendicular to the face of the carriage and later in a plane parallel to the face. Microscope readings were taken on the wire at the upper and lower limits of travel of the carriage and the position of the guide rod corrected by adjust-

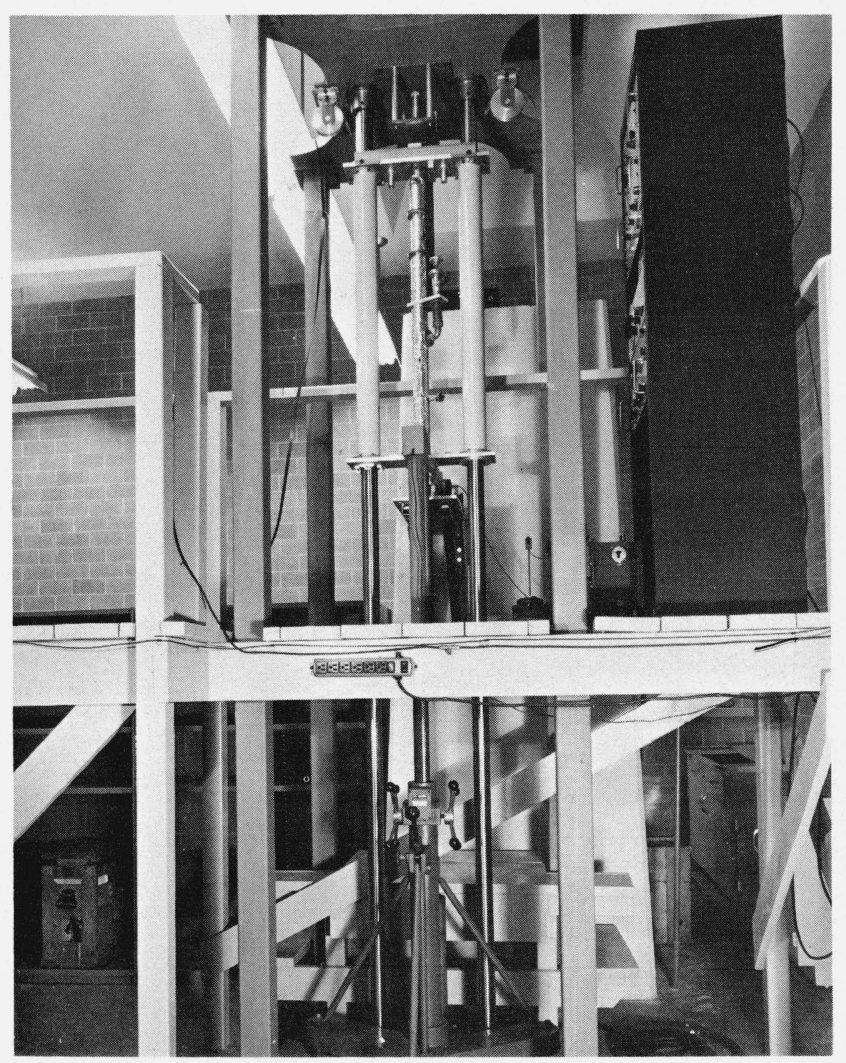

FigURE 6. General view of gravity machine. ing the centering screws in the retaining rings until the motion of the carriage was parallel to the plumb line to within $0.02 \mathrm{~mm}$ in one $\mathrm{m}$.

The release latch and initial accelerating spring were mounted on a subassembly securely attached to the upper frame plate of the gravity apparatus. The arrangement of the subassembly is shown in figure 7 .

The latch was designed in such a manner that the carriage received no lateral torque or impulse when the latch was released The latch parts were ground and finally lapped in place to provide a smooth, clean separation at release.

The portion of the latch attached to the carriage was coupled to it through a bridge frame anchored at the upper ends of the two aluminum alloy tubes that formed the vertical members of the carriage (fig. 5). This method of mounting insured that the upper plate of the carriage would not be subjected to bending due to suspension at its center. Consequently there would be no sudden release of stored energy to be transmitted directly to the vacuum chamber.

When the carriage was suspended from the latch, it was also in contact with the plunger of the initial accelerating spring. The accelerating spring assembly consisted of a precompressed helical spring contained in an adjustable barrel with provision to adjust both the force exerted by the spring and the vertical travel over which the plunger remained in contact with the carriage. These parameters controlled the amount of separation between the silica tube and the vacuum chamber support cone. As adjusted in practice, the spring exerted a force equal to approximately ten percent of the weight of the carriage and followed the carriage for about $8 \mathrm{~mm}$ in its downward travel after release of the latch. The spring assembly appears as the knurled and threaded barrel located just above the latch in figure 7.

The range of the acceleration spring adjustment was such that it was possible to adjust from a condition where the silica tube separated only momentarily

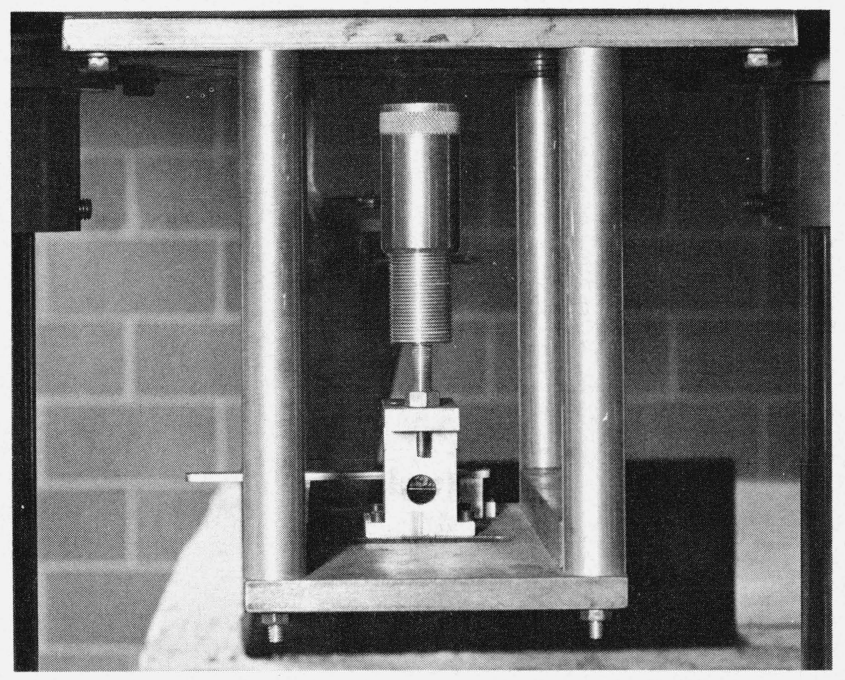

FigURE 7. Latch assembly with accelerating spring. 
from the supporting cone to a condition where the last aperture on the silica tube was no longer in line with the vacuum chamber optical window at the time it passed the sensing station. The actual operating condition was chosen at an intermediate value where the observed transit times were independent of the accelerating spring adjustment.

The vacuum chamber was attached to the carriage of the apparatus by centering screws so arranged that the upper and lower flanges of the chamber each rested against two adjustable screw stops on the longitudinal and transverse axes of the carriage. At each end a locking screw acting along a line at $45^{\circ}$ to the screw stops held the flange in firm contact. This arrangement permitted the entire vacuum chamber to be removed from the carriage and then replaced without disturbing the alinement.

In the process of alining the vacuum chamber in the carriage, rotational orientation was established by observing the superposition of the images of a point light source reflected from the upper optical window of the chamber and from a glass flat in contact with the upper cross plate of the carriage. The optical axis of the sensing station was alined to be perpendicular to the same reference plane.

The apparatus was provided with a pneumatic receiving cylinder on the lower plate of the frame and a plunger attached to the lower crossplate of the carriage to bring the carriage to a stop at the end of its fall. The plunger was machined to fit the cylinder with a radial clearance of about $0.5 \mathrm{~mm}$. A lubricated O-ring in a groove in the plunger completed the air seal between cylinder and plunger. The receiving cylinder was $56 \mathrm{~cm}$ long and $10 \mathrm{~cm}$ in diameter. A 5-m length of high-pressure type rubber tubing was connected to the cylinder through a port at the lower end. The other end of the tubing was connected to a closed-end section of larger diameter tubing. This combination provided damping to reduce the tendency of the carriage to rebound after being brought to a stop.

\subsection{Optical System}

The optical system of the position sensing aparatus is shown in figure 8 with the photomultiplier cell housing slightly retracted. This assembly was mounted on a steel bracket attached to a concrete pier directly behind the gravity apparatus (see figs. 3 and 6 ). The lens, a 100-mm microscope objective lens, focussed an image of the aperture plate edge on a slit mounted in the focal plane of a microscope eyepiece in the viewing system housing. This arrangement permitted an observer to focus the instrument by eye and to aline the slit with respect to the image. Once the alinement was completed, the optical system was terminated by the photomultiplier cell mounted in the sliding housing and making a light-tight seal to the viewing housing. The slit in the viewing system was approximately $4.5 \mathrm{~mm}$ long and $0.075 \mathrm{~mm}$ wide. The width of the slit was not critical and could have been much narrower since the output of the photomultiplier reached a maximum value in a $10-\mu \mathrm{m}$ travel of the silica tube. As the magnification of the viewing

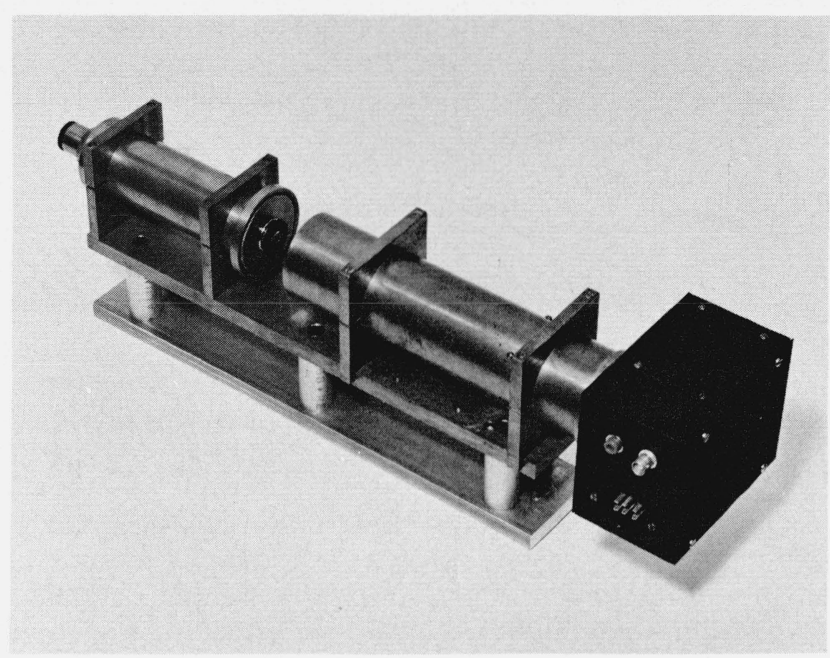

Figure 8. Optical system with photomultiplier assembly.

lens was approximately unity, a slit 10 to $12 \mu \mathrm{m}$ wide would have been adequate. The wider slit was chosen in preference, however, since during the preliminary adjustment by eye, a narrow slit produces diffraction patterns making alinement and focussing of the images difficult.

The photomultiplier tube used was a 10-stage, head-on tube having a maximum response in the spectral region of 400 to $500 \mathrm{~nm}$. The tube was operated at a cathode potential of $900 \mathrm{~V}$. The photomultiplier tube anode was connected directly into a coupling amplifier. The coupling amplifier provided a lowcapacitance, $51,000 \Omega$ load on the photomultiplier anode. The anode potential was $6 \mathrm{~V}$. The output of the coupling amplifier was connected to a $90-\Omega$ terminated coaxial cable leading to the timing system.

The light source was an incandescent filament, galvanometer lamp operated at $6 \mathrm{~V}$, direct current. The lamp had a straight, helical coil filament. The lamp was housed in a case having a lens on a focussing mount. The lens projected a roughly parallel beam of light which, with a vacuum chamber window in line with the axis, passed through the chamber window, through the transparent portion of the fused silica tube and provided a uniform illumination to the aperture edge plates mounted on the opposite side of the silica tube. The light source was mounted on a special telescope stand to facilitate levelling and positioning.

\subsection{Electronic System}

The power supplies employed for the apparatus included a low voltage direct current power supply for the light source and a high voltage direct current power supply for the photomultiplier tube. The signals from the photomultiplier tube were coupled by a coaxial cable into the input amplifier of a fastrise cathode ray oscilloscope. The triggering circuit of the oscilloscope was adjusted to start the sweep circuit at some potential level of the linearly rising (negative) signal from the photomultiplier tube. The 
timers were then triggered from the sawtooth sweep circuit of the oscilloscope. This arrangement offered a high degree of flexibility in adjustment plus very good isolation between the timers and the photomultiplier tube.

The timers were especially designed for the apparatus and sequence of signals employed. A master unit contained all the gating circuits required, a $1-\mathrm{MHz}$ thermostatted quartz crystal oscillator coupled to a $10 \times$ frequency multiplier, the shaper, and a sevenplace decimal counting unit. A second slave unit carried another seven-place decimal counting unit. Both counting units had a least count of one-tenth of a microsecond.

The timers were so coupled that on receipt of a signal from the oscilloscope the gates to both the master unit and the slave unit were opened, starting both decimal counting units. Upon receipt of a second signal, the gate to the decimal counting unit in the master timer was closed, leaving the gate to the slave unit open. The receipt of a third signal closed the gate controlling the slave unit.

The timers were provided with an optional circuit such that an interval displayed on the indicator panel could be retained while the gates were reset for a new timing sequence. Subsequent intervals were then added to the intervals already displayed. This circuit was not employed in the measurements on the falling silica tube but was utilized in assessing the errors of the gating circuits as described later.

\section{Reference Standards}

\subsection{Length}

The standard of length for the determination was an invar, l-m line standard having an $\mathrm{H}$-shaped crosssection. The scale was fabricated and ruled by the Société Genevoise d'Instruments de Physique of Geneva, Switzerland, in 1959. The scale was ruled in $1-\mathrm{mm}$ intervals with line widths of about $5 \mu \mathrm{m}$. The coefficient of expansion of the invar was determined as 0.00000123 per degree Celsius.

The lengths of $0-300 \mathrm{~mm}$ and $0-1000 \mathrm{~mm}$ intervals on the scale have been compared to the standards of the United States periodically since the scale was received in February 1960. The results are shown in table 1. It was considered that the scale was very stable for an invar standard and that the results indicated no progressive drift in the lengths. Accordingly, the means of all of the reported corrections have been applied to the measurements of the fused silica tubes in the gravity determinations.

\subsection{Time}

The standard of time for the determination was based on the National Bureau of Standards frequency standards, since only time intervals were measured. The crystal controlled oscillator of the master timer was compared to a $1,000-\mathrm{Hz}$ signal derived from the Bureau's quartz oscillator, which, in turn was com-
TABLE 1. Calibrations of invar line standard No. 5727

\begin{tabular}{|c|c|c|c|}
\hline \multirow{2}{*}{$\begin{array}{l}\text { Date of } \\
\text { calibration }\end{array}$} & \multicolumn{2}{|c|}{ Corrections to nominal lengths } & \multirow{2}{*}{$\begin{array}{l}\text { Estimated limits } \\
\text { of error }\end{array}$} \\
\hline & $\begin{array}{l}0 \text { to } 300-\mathrm{mm} \\
\text { interval }\end{array}$ & $\begin{array}{l}0 \text { to } 1000-\mathrm{mm} \\
\text { interval }\end{array}$ & \\
\hline $\begin{array}{l}\text { September } 1960 \\
\text { October } 1961 \\
\text { November } 1962 \\
\text { April } 1964 \\
\text { December } 1965\end{array}$ & $\begin{array}{ll}\mathrm{m} \times 10^{6} & \\
(\mathrm{a}) & -0.37 \\
& -.22 \\
& +.03 \\
& -.20\end{array}$ & $\begin{array}{r}\mathrm{m} \times 10^{-6} \\
+1.16 \\
+1.10 \\
+1.55 \\
+1.55 \\
+1.29\end{array}$ & $\begin{aligned} & \mathrm{m} \times 10^{-6} \\
& \pm 0.20 \\
& \pm .20 \\
& \pm .40 \\
& \pm .30 \\
& \pm .30\end{aligned}$ \\
\hline $\begin{array}{l}\text { Mean correction } \\
\text { Standard deviation }\end{array}$ & $\begin{array}{r}-0.19 \\
.17\end{array}$ & $\begin{array}{r}+1.33 \\
.21\end{array}$ & \\
\hline
\end{tabular}

pared on a daily basis to the WWV frequency standard.

The comparison of the master timer with the $1,000-\mathrm{Hz}$ reference signal was accomplished by starting the timer with a single sweep of the oscilloscope triggered from the reference signal. After an interval of approximately 100 seconds the oscilloscope sweep was reset and again triggered by the $1,000-\mathrm{Hz}$ signal. Even though the interval displayed was not exactly 100 seconds, it was some integral multiple of $1,000 \mu \mathrm{s}$. Since the difference between the crystal oscillator of the timer and the frequency standard never exceeded $50 \mu \mathrm{s}$ in $100 \mathrm{~s}$, there was no ambiguity in determining the relative error of the timer frequency base.

The crystal oscillator was checked prior to each free-fall determination and again after it. Although, as indicated above, the oscillator was always maintained within 5 parts in $10^{8}$, the observed corrections were applied to all time interval measurements.

\section{Techniques of Measurement}

\subsection{Length}

Measurements of the two lengths, $L_{1}$ and $L_{2}$, were carried out using the same apparatus employed in the free-fall determinations. The weight of the carriage was balanced by means of the steel tapes running over the frame pulleys with appropriate weights on the other ends of the tapes. The invar length standard was attached in holders beside the vacuum chamber in such a position that the rulings on the speculum surface could be viewed by a reading microscope attached to the support table for the position sensing apparatus. A fine motion drive was attached to a guide rod and served to advance the carriage by the small motions required.

Basically the procedure consisted of moving the carriage to a position where the lower aperture on the silica rod was in a position with respect to the sensing station such that the output signal from the photomultiplier cell was at the same potential as that which would trigger the oscilloscope-timer combination. At this point a reading was taken on the zero ruling of the invar scale with a filar micrometer on the reading microscope. The carriage was then moved on to bring the second aperture into line with the sensing station and a microscope reading taken 
on the $300-\mathrm{mm}$ graduation of the invar scale. The process was repeated again for the upper aperture and the $1,000-\mathrm{mm}$ graduation.

It will be seen that this process is one of measuring how far the silica tube must be moved to produce the triggering signals rather than of measuring its length. This method of measurement has the advantage of including the effects of vacuum on the silica scale as well as any possible displacement of the images by the optical windows of the vacuum chamber. More important, since there are complex diffraction effects at a shadow edge, the measurement is related directly to the conditions present in the experiment and measures directly the quantity sought.

The reading microscope used for the observations on the invar scale was mounted on the base plate for the optical system. Provision was made for the microscope base to be attached on either side of the position sensing system. The microscope was mounted on a special base with a rack and pinion focussing control and a fine adjustment screw. The microscope tube length was $215 \mathrm{~mm}$ with a 22.5- $\mathrm{mm}$ objective and a $12.5 \times$-filar micrometer eyepiece. The filar micrometer eyepiece was equipped with double cross-hairs spaced the equivalent of $12 \mu \mathrm{m}$ in the object plane. The micrometer drum was graduated into 100 divisions per revolution. The reading microscope was calibrated on an auxiliary scale and had a factor of $1.112 \mu \mathrm{m}$ per division. During observations the micrometer drum was read to one tenth of a division. In no case was it necessary to measure differences exceeding 50 divisions with the filar micrometer eyepiece.

During length measurements it was necessary to locate the carriage in a position where the output from the phototube amplifier was at the potential required to trigger the timing system. A direct current voltmeter with a trimmer was connected in parallel to the output of the amplifier and adjusted so that it indicated full scale at the maximum output of the amplifier. The triggering potential was then set to be at the half scale reading. The indication was such that the small graduations on the voltmeter corresponded to movements of about $0.2 \mu \mathrm{m}$ at the carriage. The position could be set to a small fraction of a voltmeter division with the aid of the fine-motion drive. The meter was slow enough in response to mask the effects of photomultiplier tube noise and building vibration.

The fine-motion drive which made possible the adjustment of the carriage to the final position for reading the length standard consisted of a hinged brass clamp which could be opened, slipped around a steel guide rod and locked in place. A bronze spring provided sufficient frictional drag on the smooth rod to hold the clamp against the 100- or 200-g unbalanced weight of the carriage, yet permitted the clamp to be slid by hand as a coarse adjustment. Attached to the clamp was a flat wedge, driven by a fine thread screw, actuating a small push rod to move the carriage.

\subsection{Temperature}

The invar length standard was equipped with two mercury-in-glass thermometers, one mounted near the center of the 0 to $30-\mathrm{cm}$ length and the other near the upper end of the scale. The thermometers were graduated to $0.2 \mathrm{deg}$ Celsius and had errors less than $0.02{ }^{\circ} \mathrm{C}$ at the ambient temperature of the room $\left(22^{\circ} \mathrm{C}\right)$. The thermometers were mounted against the back surface of the web of the $\mathrm{H}$-section of the length standard; the bulbs were packed in aluminum foil compressed against the surface of the invar and covered by $6 \mathrm{~mm}$ of cork sheet up to the graduated portions of the stems. The exposed portions of the cork pads were covered with a layer of aluminum foil.

A similar thermometer was mounted in contact with the lower section of the vacuum chamber. The chamber was covered by a 6-mm layer of cork sheet topped by a double layer of aluminum foil. While it was recognized that the temperature of the silica tube was not necessarily the same as the temperature of the chamber wall, it was assumed that the tube temperature maintained a reasonably constant relationship to it, once thermal equilibrium was established. The temperature of the vacuum chamber walls during length measurements averaged about $0.2{ }^{\circ} \mathrm{C}$ less than that during the free fall measurements. This difference probably was caused by the larger number of pieces of electronic equipment operating during the free fall measurements.

\subsection{Compensation for Guide Curvature}

The two guide rods, previously described, on which the carriage ran were of a special case-hardened steel, centerless ground and selected for straightness. The diameters were $63.47 \pm 0.020 \mathrm{~mm}$ and the rods were straight within $80 \mu \mathrm{m}$ per meter. These tolerances were quite adequate for operation in the free-fall phase of the experiment but the slight curvature of the rods was sufficient to make an appreciable error in the length measurement. The error is proportionate to the product of the angle of rotation of the carriage and the distance between the axis of the invar scale and the silica tube.

If the position of the silica tube and the invar scale are interchanged with respect to the direction of rotation, the algebraic sign of the error is reversed. Thus the mean of two measurements with the scale interchanged between them should be free of the error due to curvation of the guide rod, provided that the rotation of the carriage is the same in both sets of measurements.

The carriage of the gravity apparatus was provided with duplicate sets of holders for the invar scale, one set on each side of the vacuum chamber equidistant from the centerline of the silica tube. A length measurement consisted of two sets of measurements, one for each location of the invar scale. The final computed lengths from each set were averaged to obtain a working value. Ordinarily the first set of measurements was made at the start of a day. Upon completion of the first set, the invar scale was transferred to the opposite set of holders; about five hours later the second set of measurements was made. The order in which the two positions were occupied was reversed on alternate days of length measurement. 
Analysis of the length measurements made on four different fused silica rods indicated that the length deviation due to curvature of the guide rod was about $1.6 \mu \mathrm{m}$ at the $30-\mathrm{cm}$ length and about $0.7 \mu \mathrm{m}$ with opposite sign at the 1-m length.

\section{Experimental Procedure}

\subsection{Length Measurements}

In the plan of the experiment, length measurements and free-fall measurements were made on alternate days. A set of length measurements consisted of ten independent determinations of the two lengths, the silica tube being reseated and realigned and the reading microscope refocussed between determinations. At the conclusion of the set the invar length standard was transferred to the opposite side of the carriage and, after a lapse of about five hours, a second set of ten measurements was made.

The procedure in each determination was always the same. After reseating the tube and focussing the microscope, the thermometers were read and the temperature recorded. The carriage was then moved to a position where the first or lower aperture was at the reference level as indicated by the meter connected to the output of the photomultiplier tube amplifier. The zero graduation of the invar scale was centered between the cross-hairs of the filar eyepiece and the filar drum reading recorded to the nearest tenth of a division. The carriage was then moved to the second aperture position and the corresponding filar reading recorded. The process was repeated for the third aperture and the carriage returned to the first aperture position where the initial reading was repeated.

For the calculation of the two lengths, any change between the first and final lower aperture readings was assumed to be due to thermal drift, and values corresponding to the second and third aperture readings were obtained by interpolation with respect to the average time required for the operation. Any run in which the first and final lower aperture readings changed by more than $2 \mu \mathrm{m}$ was discarded as such changes were apt to be caused by actual movement of the silica tube in its seat.

The lengths of the $30-\mathrm{cm}$ and $1-\mathrm{m}$ aperture distances were computed from the observed filar readings, the calibrated lengths of the invar standard intervals and the temperature correction for the invar standard $\left(1.23 \times 10^{-6}\right.$ per degree Celsius). The measured lengths of the silica tube aperture intervals were corrected to $22{ }^{\circ} \mathrm{C}$ for comparison using an experimentally determined coefficient of $0.64 \times 10^{-6}$ per degree Celsius. Since the temperature at which the free-fall measurements were made was close (within $0.2{ }^{\circ} \mathrm{C}$ ) to that of the length measurements, coefficients of expansion were not determined separately for each of the four silica tubes used in the experiment.

\subsection{Timer Adjustments}

During the free-fall determinations, the times for the passage of the $30-\mathrm{cm}$ length interval and for the 1-m interval were obtained from the two seven-decade timers already described. The smallest unit of time so displayed was one-tenth microsecond. Two corrections were applied to the time measurements. A correction for frequency of the crystal oscillator was applied, although it was negligible compared to other sources of error. A correction for differential delay in opening and closing of the gate circuits was also necessary. The indication in the unit which displayed the time interval for the 1-m length was consistently short by nearly one-tenth of a microsecond due to an electronic delay in opening the counting gate for this bank.

The gating errors for time interval meters were assessed by presenting the system with a series of pulses generated by a decimal dividing network and a crystal controlled test oscillator. The pulses were generated at intervals of $10 \mathrm{~ms}$ and the timers measured the time for a single and double pulse interval. A total of one hundred such measurements were summed in the counter banks of the timers. Since the mean of such a group of measurements tends to eliminate random effects, the result should reflect the systematic error in the time measurement system. It is assumed that the pulse source contained only random variations since it was a continuous system and the test oscillator was synchronized with the time interval crystal frequency to better than one part in ten million.

\subsection{Free-Fall Measurements}

Free-fall measurements were made on days alternating with length measurements. The free-fall measurements normally consisted of two sets of 16 determinations, one set being made at the start of the day and one set at the end of the day.

The first steps in the free-fall measurements entailed determinations of the crystal frequency error and the mean gating errors for both channels. The timing system was connected to the $1,000-\mathrm{Hz}$ reference signal and the time for approximately 100,000 cycles measured. The input and triggering circuit used was the same as that used for the photomultiplier cell. The departure from the nominal multiple of $1,000 \mu \mathrm{s}$ indicated the crystal frequency error in $100 \mathrm{~s}$. Single cycle measurements of the period of the $1,000-\mathrm{Hz}$ standard signal, as received, all fell within a band of $\pm 0.2 \mu \mathrm{s}$, about the average value of the period. A group of measurements over $100 \mathrm{~s}$ (approximately $10^{5}$ cycles) showed a standard deviation of $0.9 \mu \mathrm{s}$, approximately one part in $10^{8}$. After the crystal frequency error was measured, single and double individual period measurements were made on a decade divider pulse signal at a frequency of $100 \mathrm{~Hz}$. The timers were operated to total 100 such measurements and the mean gating errors computed from the two sums indicated by the timers.

After these values had been recorded, the valve in the vacuum pump line was closed and the pump disconnected. The vacuum pressure was read, the gage indicator disconnected, and the timing system connected to the cable of the photomultiplier cell. 
At this point the system was ready for the time measurements on the falling silica tube. The silica tube was alined in the vacuum chamber by means of the upper guide bearing mechanism and the guide bearing was retracted and locked in place. The vacuum chamber wall temperature was recorded and the release latch opened, permitting the carriage to fall. At the conclusion of the fall the carriage was immediately returned to the latched position and the two time intervals recorded. The silica tube was realined in the chamber and the apparatus was ready for the next determination.

During the set of measurements, the wall temperature of the vacuum chamber was recorded for every fifth drop of the carriage. At the conclusion the vacuum pressure was read and the frequency and gate error measurements repeated. The entire set of measurements required about three-quarters of an hour.

\section{Results}

\subsection{Experimental Data}

Four different fused silica tubes were included in the experiment. There were five sets of length measurements for each tube, a set consisting of two sub-sets made with the invar length standard on alternate sides of the vacuum chamber as outlined in the section on length measurements. Bracketted between each pair of sets of length measurements were two sets of freefall measurements. A set of free-fall measurements consisted of about sixteen individual free falls of the apparatus. A few sets contained only fifteen observations and some sets contained as many as twenty-one. Since five sets of length measurements provide four adjoining pairs, there were normally eight sets of free-fall measurements for each tube.

There were two exceptions to this general rule. In the case of tube No. V, four free-fall measurements were included between the first two pairs of sets of length measurements, changing the total to twelve. In the case of tube No. VI, a readjustment of the optical system of the position sensing station became necessary after the conclusion of the third set of length measurements. The adjustment was made and a new set of length measurements inserted to go with the succeeding free-fall measurements.

A summary of the length measurements for the four silica tubes is given in table 2. Each entry in the table represents the mean of two sub-sets of 10 independent measurements. From the standard deviations of the individual sub-sets an estimate was made of the average standard deviation of the measured length intervals reported in the table. The standard deviations were approximately $0.14 \mu \mathrm{m}$ for both the $30-\mathrm{cm}$ and the 1-meter intervals. It is evident that the variations in length appearing in the table are partly random and partly due to real changes. In order to obtain adjusted length values corresponding to the free-fall measurements the data were treated as though all differences were real and as though the changes took place at a uniform rate during the course of the intervening free-fall operations. Accordingly, the ad-
TABLE 2. Measured length intervals for fused silica tubes

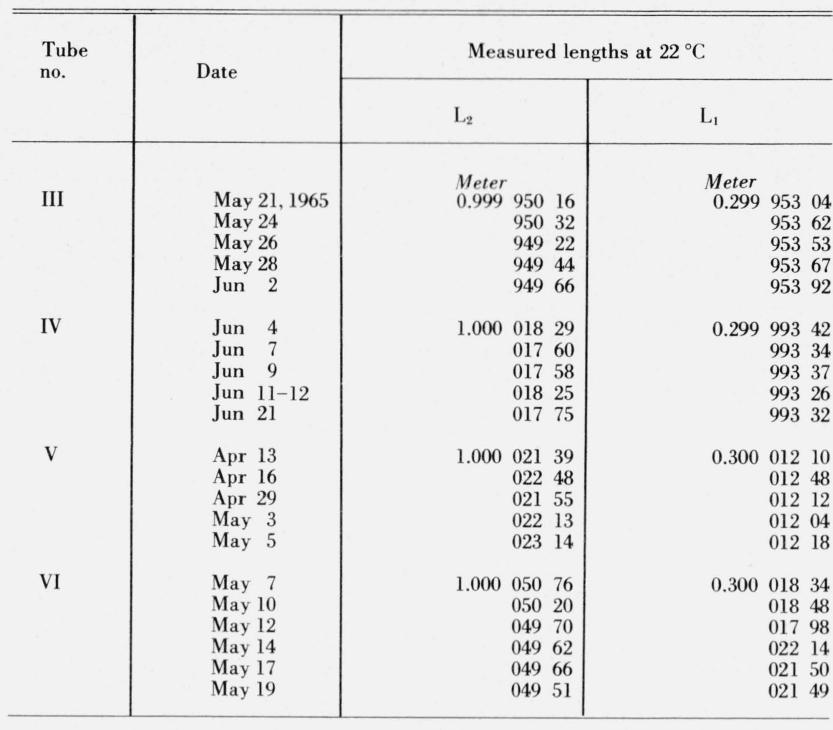

Note: Between the observations on the dates of May 12 and May 14 an adjustment was made to the lens diaphragm of the viewing system.

justed length intervals were calculated by linear interpolation between adjacent measured length intervals. The adjusted values were then corrected from $22^{\circ} \mathrm{C}$ to the observed chamber temperature for each set of free fall measurements. The adjusted and corrected length interval values appear in table 3.

The time intervals presented in this table are the mean times determined from each set of free-fall observations after correction for both frequency and gating errors as described in the section on time measurements. The corresponding values of the acceleration due to gravity are calculated from the relationship

$$
g=\frac{\frac{L_{2}}{t_{2}}-\frac{L_{1}}{t_{1}}}{1 / 2\left(t_{2}-t_{1}\right)}
$$

The values in the final column are the standard deviations of the gravity values computed from the distribution of the pairs of individual free-fall time measurements about the two mean intervals for each set of free-fall observations. The standard deviation of an individual free-fall determination may be calculated by multiplying the standard deviation of the mean by the square root of the number of observations in the set, given in parentheses.

The mean values of the gravity measurements for each of the four tubes are presented in table 4 . The standard deviations for the means were calculated from the distributions of the individual set means. The final result was computed as the unweighted mean of the four tubes. The mean of the 36 individual sets gives the same value. 
TABLE 3. Free-fall time and length measurements

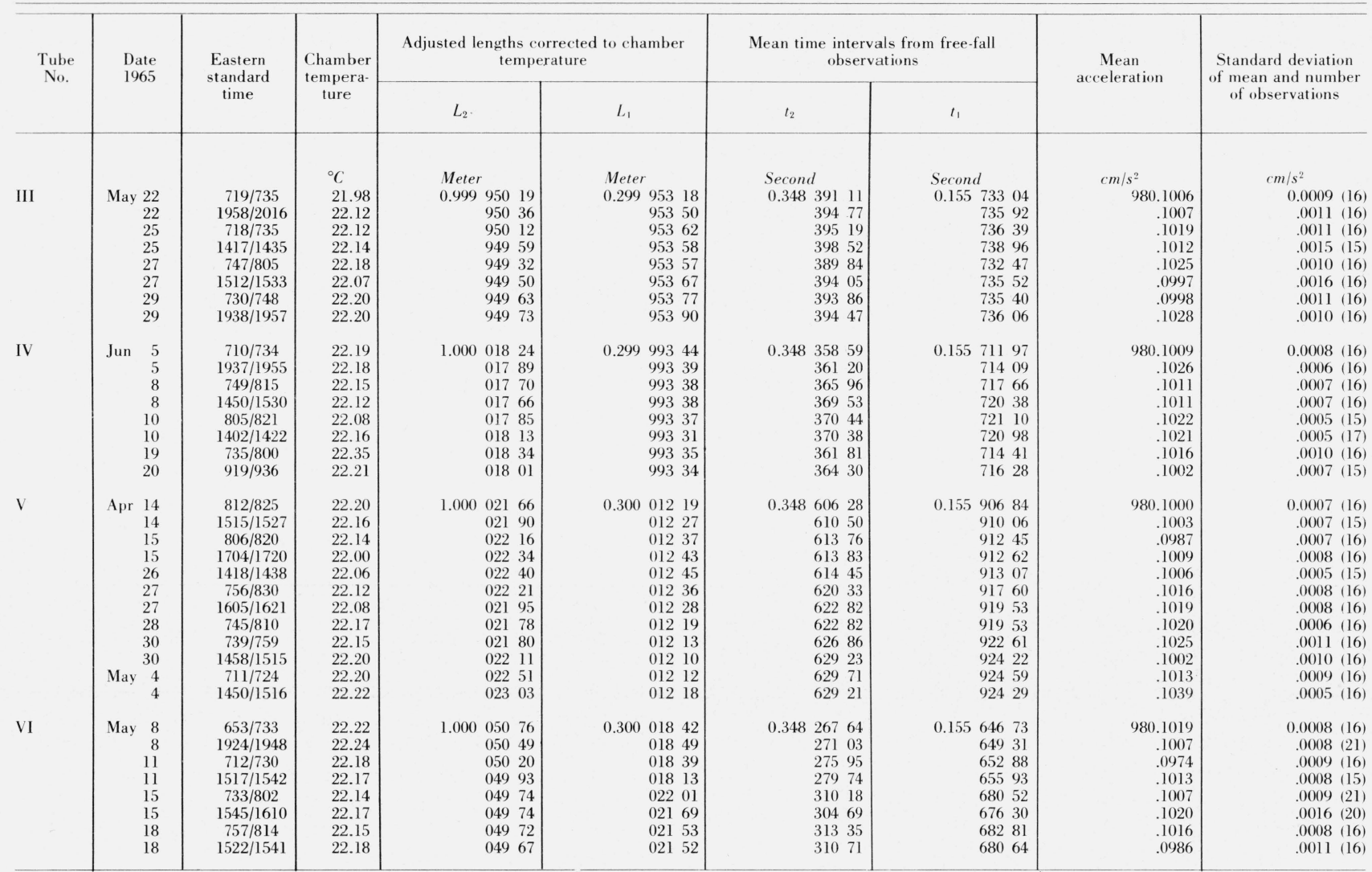

TABLE 4. Summary of gravity values

\begin{tabular}{c|c|c|c}
\hline \hline $\begin{array}{c}\text { Tube } \\
\text { No. }\end{array}$ & $\begin{array}{c}\text { Number } \\
\text { of sets }\end{array}$ & $\begin{array}{c}\text { Mean acceleration } \\
\text { due to gravity }\end{array}$ & $\begin{array}{c}\text { Standard deviation } \\
\text { of the mean }\end{array}$ \\
\hline & & $c m / s^{2}$ & $c m / s^{2}$ \\
III & 8 & 980.1012 & 0.0004 \\
IV & 8 & 980.1015 & .0003 \\
V & 12 & 980.1012 & .0004 \\
VI & 8 & 980.1005 & .0006 \\
\hline \multicolumn{2}{|l}{$\begin{array}{c}\text { Unweighted mean } \\
\text { of four tubes }\end{array}$} & 980.1011 & 0.0002 \\
\hline
\end{tabular}

\section{Sources of Bias}

There are several potential sources of systematic error in an experiment of this type. Although the amounts of error contributed cannot always be evaluated accurately, limits can usually be set for them. It is considered that the principal contributions to error in the results of this measurement are the following: longitudinal vibration of the falling tube, electrostatic and magnetic forces, residual air in the vacuum chamber, lateral deflection of the falling object, effects from the optical windows of the chamber, time constants of the electronic circuits, and uncertainty in the length standards and measurements.

\subsection{Longitudinal Vibration}

At the instant of release the fused silica tube rests on the support cone which, upon release, moves downward with an acceleration about 10 percent in excess of gravity. It is reasonable to expect that the release of the slight compression of the silica tube would cause it to vibrate longitudinally while falling. As the displacement of the various parts of the tube would cause an error in time indication, the magnitude of the error is worth examining.

The largest amplitudes would be those due to the first mode of vibration in which there is a maximum amplitude at the extremities of the tube and a node at the center. For a fused silica tube or rod with density $2210 \mathrm{~kg} / \mathrm{m}^{3}$, modulus $7.2 \times 10^{10} \mathrm{~N} / \mathrm{m}^{2}$, and a length of one meter, the undamped frequency of the first mode is about $2850 \mathrm{~Hz}$, corresponding to a period of 350 microseconds. The static compression of the tube relative to the center of mass would be $0.113 \mu \mathrm{m}$ and the maximum harmonic acceleration under these conditions would be $3620 \mathrm{~cm} / \mathrm{s}^{2}$. Since this acceleration is greater than that of the support (approximately $1080 \mathrm{~cm} / \mathrm{s}^{2}$ ), the surfaces cannot separate until the elastic deformation is reduced to a point where the sum of the harmonic acceleration and the acceleration of the center of mass is less than $1080 \mathrm{~cm} / \mathrm{s}^{2}$. 
Assuming the limiting case in which the acceleration of the center of mass prior to separation is assumed to be zero, the separation would occur at about 71 $\mu \mathrm{s}$ after the release is initiated, approximately 81 percent of the first quarter period. At this point the common velocity of the two parts is determined by the velocity of the uniformly accelerated support, about $0.0765 \mathrm{~cm} / \mathrm{s}$. The resultant undamped amplitude of vibration of the fused silica tube corresponding to this speed and displacement would be $0.045 \mu \mathrm{m}$. The maximum effect of such an amplitude would result in an error less than $0.0003 \mathrm{~cm} / \mathrm{s}^{2}$ in an individual measurement. Such an error represents the upper limit possible. The calculation has not included motion of the center of mass of the silica tube which would necessarily occur with a consequent reduction in the harmonic velocity at the time of separation. Furthermore, the silver conductive coating on the tube would add considerably to the damping of the vibration.

It is considered that errors of the above magnitude would not occur consistently in a long series of measurements and can thus be considered negligible.

\subsection{Electrostatic Forces}

It has been the experience of most investigators in free-fall gravity experiments that electrostatic forces constitute a major source of difficulty. The separation of any two surfaces, particularly in a vacuum, usually leaves them in a charged condition. It is not necessary for the surfaces to slide in order to produce the charges. If one or both surfaces are poor conductors, the charges may remain highly localized and the electrostatic forces arising from the interaction of the intense fields may be quite substantial. The introduction of radioactive materials into the chamber offers little help as the gas pressure is too low to afford many ions and the time too short for them to dissipate the charges effectively.

In some early experiments with the apparatus described here, a fused silica rod was provided with a polytetrafluoroethylene tip. The charge generated by the separation of the tip from its seat was sufficient to draw the falling rod several millimeters out of its path during the 0.5 -s fall.

The electrostatic charge problem can usually be solved by making the entire falling object electrically conductive. In the case of the fused silica tubes employed in this experiment, the objective was attained by coating the transparent tubes with silver conductive paint of the type used for printed circuit assemblies. The end-to-end resistance of the tubes ranged from 4 to $10 \Omega$. The tubes were coated on the outsides leaving uncoated only small areas in line with the slit apertures. Since it was possible to vary the separation between the tube and the support cone during the fall by changing the force applied by the initial accelerating spring, it could be ascertained that any remaining electrostatic attraction was below the limit of detection.

\subsection{Magnetic Forces}

Magnetic forces are not usually a substantial factor in free-fall gravity measurements provided the falling object can be constructed of nonferromagnetic materials. In the experiment described here, three of the tubes employed contained small amounts, less than $300 \mathrm{mg}$ each, of steel in the form of thin plates for the aperture edges. The other tube, No. III, contained no ferromagnetic materials. Since the magnetic field of the earth was fairly uniform along the line of fall of the silica tube, it is considered that the net effect of magnetic attraction on the tube was negligible.

Effects caused by eddy currents would likewise be small. An analysis by E. C. Lloyd ${ }^{3}$ of the National Bureau of Standards expresses the average ratio of the force due to eddy current losses to the gravitational force, $F_{m} / F_{g}$, for a conducting tube falling through a magnetic field discontinuity which is short compared to the length of the tube.

$$
\frac{F_{m}}{F_{g}}=\frac{A^{2} t \sigma(\Delta H)^{2}}{1.27 m(\Delta l)} \times 10^{-12}
$$

where $A=$ area enclosed by the tube, square meter,

$t=$ time of fall, second,

$\sigma=$ circumferential conductivity of the tube, mho/meter,

$m=$ mass of the tube, kilogram,

$\Delta l=$ length of the magnetic discontinuity, meter,

$\Delta H=$ change in magnetic field strength, ampere/ meter.

For the experiment described here, $A=1.87 \times 10^{-4} \mathrm{~m}^{2}$, $t=0.35 \mathrm{~s}, \sigma=100 \mathrm{mho} / \mathrm{m}, m=0.1 \mathrm{~kg}$. If one assumes a value for $\Delta l$ of $0.01 \mathrm{~m}$ and for $\Delta H$ of $12 \mathrm{~A} / \mathrm{m}$,

$$
\frac{F_{m}}{F_{g}}=1.3 \times 10^{-13} \text {. }
$$

\subsection{Residual Air}

The principal effects of air on a falling object are the buoyant forces due to the density gradient in the air and the viscous drag resulting from relative motion of the object. The buoyant effect with fused silica is less than 600 parts in one million at atmospheric pressure and, since it varies in direct proportion to the pressure, can be considered negligible at pressures below $16 \mathrm{~N} / \mathrm{m}^{2}$. In the experiment the pressure at no time exceeded $1.5 \mathrm{~N} / \mathrm{m}^{2}$. The average pressure during the 36 sets of free-fall measurements was $0.4 \mathrm{~N} / \mathrm{m}^{2}$.

The viscous drag effects of air on a falling object are more complex. At pressures above $100 \mathrm{~N} / \mathrm{m}^{2}$ the inertial effects of the gas tend to be the predominant factor, while at lower pressures the predominant factor tends to be momentum transfer from molecular collisions with the object. Both effects overlap and there are no sharp boundaries between them. Cook [16] (Section 5.3) has discussed several cases and has shown that, at low pressures for a rod of radius $r$ and density $\rho$, the ratio of the molecular forces to the gravitational forces would be expected to be less than

$$
\frac{F_{m}}{F_{g}}=\frac{C \alpha}{2 \rho r g} U
$$

\footnotetext{
${ }^{3}$ Informal communication to the author, January, 1962.
} 
where $\alpha$ is the gas density, $C$ is the average molecular velocity, and $U$ is the object speed. The gas pressures present in this experiment were such that the Stokes law forces would be expected to be of the same order of magnitude or less.

$$
\text { If } \alpha=5 \times 10^{-12} \mathrm{~kg} / \mathrm{m}^{3}, C=5 \times 10^{2} \mathrm{~m} / \mathrm{s} \text {, }
$$

$$
r=7.5 \times 10^{-3} \mathrm{~m}, \rho=2 \times 10^{-3} \mathrm{~kg} / \mathrm{m}^{3},
$$

and $U=2 \times 10^{-3} \mathrm{~m} / \mathrm{s}$, the ratio would be of the order of

$$
\frac{F_{m}}{F_{g}}=0.014 \times 10^{-6} \text {. }
$$

From the estimate above it would be expected that the total effect due to residual air would be less than 0.03 parts in a million.

In the earlier course of the experiment a few determinations were made with atmospheric pressure in the vacuum chamber. Since the air in the chamber is being accelerated downward at approximately the acceleration due to gravity it might be expected that the buoyant effect would be very small. For the limited number of tests conducted, results at atmospheric pressure did not differ significantly from those obtained at the normal pressures of 0.2 to $0.5 \mathrm{~N} / \mathrm{m}^{2}$.

\subsection{Deflection of the Falling Object}

Any lateral impulse imparted to the falling tube would cause it to rotate about a horizontal axis through its center of mass. Since the reference slits lie both above and below this point and in a plane about $8 \mathrm{~mm}$ closer to the viewing microscope, the amount of error depends on the plane of rotation.

Rotations in a vertical plane perpendicular to the optical axis were measured by photographing the falling tube with a $25-\mu \mathrm{m}$ wire stretched vertically across the upper slit. The photographs were made through the microscope of the optical sensing system, using a short-duration flash synchronized with the falling tube. The photographs showed random departures on both sides of the average line of fall varying up to a maximum of $0.2 \mathrm{~mm}$.

Rotation in the plane containing the optical axis could not be measured, but there was no evidence from the sharpness of focus of the photographs that the motion exceeded that in the other plane.

The motion observed in the photographs was probably due to a combination of both lateral translation and rotation at the center of mass. Lateral translation would theoretically contribute no error.

A computation of the error due to pure rotation of the maximum observed amount was made for motion both in the plane of the optical axis and perpendicular to it. The fact that the aperture plates were located off the axis of the tube makes the computation slightly different for the two planes. The computed magnitudes of the errors were approximately the same for both cases, however, about $8 \times 10^{-8} \mathrm{~g}$.

Errors due to rotation in the plane containing the optical axis are positive or negative according to the direction of rotation and thus are not likely to con- tribute systematic error. Rotation in a plane perpendicular to the optical axis always results in a value of gravity which is too high, but it would be expected that the average systematic error would not exceed $0.05 \mathrm{mGal}$. It did not appear feasible to apply a correction for this error as it could not be determined which part of the $0.2-\mathrm{mm}$ maximum displacement of the wire image was due to rotation and which part was due to lateral translation.

\subsection{Ground Motion}

No attempt was made to measure seismic ground motion during the observations. It is considered that the greatest effect would arise from microseisms with periods on the order of $0.7 \mathrm{~s}$. It was considered preferable to operate the release without regard to the existing amplitude and phase of the ground motion rather than to observe the seismic motion and time the release for optimum conditions. In effect this represents accepting a larger but purely random variability in preference to a smaller but less purely random one.

One source of ground movement which can operate to produce systematic bias, however, is the shock wave resulting from the release of the falling object. In the present experiment, the mass of the moveable carriage with the vacuum chamber was of the order of $22 \mathrm{~kg}$.

The transient disturbance introduced by the release of the $22-\mathrm{kg}$ carriage was studied with the aid of a Johnson-Matheson seismometer having a frequency range of approximately one to five cycles per second. The measurements indicated that the pier to which the position sensing station was attached experienced a sharp upward impluse from the release of the car and returned to its original level within about 70 to $80 \mathrm{~ms}$. The amplitude of the motion was on the order of 0.15 to $0.2 \mu \mathrm{m}$. The motion appeared to be heavily damped as there was no appreciable overshoot on the return. Random motion of the pier due to other disturbances within the building at times produced motions of the same order of magnitude.

Since the time measurements for the gravity determination were not initiated until about $118 \mathrm{~ms}$ after release it is believed that the systematic effect of the shock wave from the release of the carriage was negligible.

\subsection{Effects from Optical Windows}

The vacuum chamber was equipped with three pairs of optical windows to permit observations on the fused silica tube inside. The windows, previously described, were $4.5 \mathrm{~mm}$ thick. It was at first considered that since any optical displacements which they produced were included in the static length measurements they were not likely to be the cause of systematic error. This assumption proved to be far from correct.

Initial measurements made with the apparatus produced results which showed a long-term, quasiperiodic variability which could not be accounted for 
by any reasonable assumption of either errors in the measurements or secular changes in gravity.

During these measurements the vacuum chamber was over-constrained in its attachment to the carriage, the flat parallel ends of the chamber rested between the two parallel cross members of the carriage with a light friction fit and were secured against lateral movement by centering screws. The latch from which the carriage was suspended was attached directly to the upper cross-member of the carriage just above the vacuum chamber. It was suspected that the chamber was being loaded eccentrically by distortions of the carriage frame resulting from release of the latch. If such eccentric loading should cause some elastic bending of the vacuum chamber during the fall with a resultant rotation of the optical windows, the effect could be significant.

The displacement of the image of an object viewed through a plane-parallel glass plate is sensitive to tilt of the plate. The displacement for small angles of tilt is on the order of

$$
d=T \theta\left(1-\frac{1}{N}\right)
$$

where $T$ is the plate thickness, $\theta$ is the angle of tilt and $N$ is the index of refraction. For a thickness of $4.5 \mathrm{~mm}$ and an index of refraction of 1.5 a rotation of one minute of arc will produce an apparent displacement of about $0.4 \mu \mathrm{m}$.

On the hypothesis that sufficient flexure of the chamber was taking place to produce window rotations of this order of magnitude, and that the amount of flexure would vary with slight differences of temperature between the brass chamber and aluminum alloy carriage, the vacuum chamber mount was redesigned. The chamber was slightly shortened to produce a positive clearance at the upper end in the carriage and a single point support was provided at the lower end on the central axis of the chamber.

The modification effectively eliminated the longterm variations in the observations. Later, when the apparatus was moved from the older site in the East Building of the Bureau to the new Gaithersburg site where the observations reported here were made, the carriage itself was modified. The connection between the latch and the carriage was made through two independent yokes which were attached to the carriage at points directly above the two vertical tubular structures. This arrangement eliminated the flexing of the cross-members supporting the vacuum chamber.

\subsection{Time Constants of the Circuits}

The 10-stage photomultiplier tube used in the measurements had a spectral sensitivity peak in the 400 - to $500-\mathrm{nm}$ range and was always used in the dark-to-light transition condition. Connection to the coupling amplifier circuit was less than $5 \mathrm{~cm}$ long and unshielded to minimize capacitance loading of the anode. The anode current was limited to $0.1 \mathrm{~mA}$ at full illumination. The entire phototube circuit through the coaxial cable connections to the timer panel was capable of following illumination rise times at least five times greater than those provided by the gravity apparatus.

\subsection{Uncertainty in the Length Standard}

Of the two standards employed in the measurements, length and frequency, the length standard was by far the more critical in terms of the difficulty in obtaining the desired precision in its calibrations. The standard, an H-section scale of invar was ruled by the Société Genovoise. The 1-m length was graduated into $1-\mathrm{mm}$ intervals. The width of the engraved lines was approximately $5 \mu \mathrm{m}$. Only the $0-$, the $300-$, and the $1000-\mathrm{mm}$ lines were used in the measurements. The calibrations of the scale were limited to the intervals defined by those lines.

Table 1 shows the results of the calibrations of the scale made by the Length Section of the National Bureau of Standards. No determination was made of the $300-\mathrm{mm}$ interval in the 1961 calibration because of the very small change observed in the $1000-\mathrm{mm}$ interval. The table shows that the standard deviations over the five-year period compare very favorably with the estimated limits of error for the individual determinations. Since the scale was in active use over the greater part of the five-year period, it was concluded that the stability was excellent with no significant drift. The mean corrections were selected as giving the most reliable values for the lengths of the two intervals.

Some estimate of the effect of the different length determinations obtained for the invar scale can be made by computing a series of gravity values in which the successive length corrections are the only variable. Using the adopted mean corrections as a reference, the calibrations of $1960,1962,1964$, and 1965 would have resulted in gravity values differing from the reference level by $+0.5,+0.7,-1.0$, and $-0.2 \mathrm{mGal}$ respectively. The standard deviation of the mean correction would be $0.4 \mathrm{mGal}$. This result illustrates one disadvantage in the use of an intermediary standard in a measurement requiring the greatest possible accuracy.

\subsection{Uncertainty in the Length Measurements}

As previously indicated in Section 4.1, a determination of the two lengths, $L_{1}$ and $L_{2}$, of a silica tube consisted of ten measurements of each length with the invar scale on one side of the carriage and ten measurements of each length with the scale on the other side. The two sets were averaged to give the final value. The individual sets showed good internal consistency even though a set required about one hour to complete. The standard deviation of a single length determination of either the $300-\mathrm{mm}$ or the $1000-\mathrm{mm}$ interval was usually on the order of 0.6 or $0.7 \mu \mathrm{m}$; thus the standard deviation of the mean of ten would be on the order of $0.2 \mu \mathrm{m}$. As indicated earlier, there was usually some evidence of real change in the interval lengths over the complete series of free-fall experiments.

An interesting side effect in the length measurement is the small error due to the relative shortening of the 
invar scale and the silica tube when they are supported at rest in vertical positions. The length desired is, of course, that of the silica tube in its relaxed condition in free fall. The length of the invar scale is determined in the length laboratory in a horizontal position while supported at the Bessel (Airy) points. Neglecting the slight droop of the bar between the support points, it can be considered in a relaxed condition during this comparison. If now the scale and the tube are supported on their lower ends in a vertical position, both will be compressed slightly under their own weight. The changes in lengths are in proportion to the ratio of the densities of the materials to their respective moduli of elasticity.

The decrease in length of a rod or tube standing on its lower end is given by the relationship

$$
\Delta L=\frac{\rho g}{E} \int\left(L_{0}-y\right) d y
$$

where $\Delta L$ is a change in length, $\rho$ is the density, and $E$ is the modulus of elasticity. If the origin is taken as the bottom of the tube, at $y=L_{0}$ the integral has the value

$$
\Delta L=0.5 \frac{\rho g}{E}
$$

and at $y=0.3 L_{0}$ the integral is

$$
\Delta L=0.255 \frac{\rho g}{E} \text {. }
$$

The fused silica used in the tubes had a density of approximately $2210 \mathrm{~kg} / \mathrm{m}^{3}$ with a modulus of $7.2 \times 10^{10}$ $\mathrm{N} / \mathrm{m}^{2}$. Invar has a density of approximately $8000 \mathrm{~kg} / \mathrm{m}^{3}$ and a modulus of $14.8 \times 10^{10} \mathrm{~N} / \mathrm{m}^{2}$. The computed corrections for the tubes and invar length standard are as follows:

\begin{tabular}{l|c|c}
\hline \hline & $\begin{array}{c}30-\mathrm{cm} \\
\text { interval }\end{array}$ & $\begin{array}{c}\text { 1-meter } \\
\text { interval }\end{array}$ \\
\cline { 2 - 3 } & $\mu m$ & $\mu m$ \\
Invar & -0.14 & -0.26 \\
Silica & -0.08 & -0.15 \\
Difference & -0.06 & -0.11 \\
\hline
\end{tabular}

Although these corrections are below the level of significance in the measurements, the differences were systematic and were applied in the adjustment of the lengths of the fused silica tubes.

Since the temperature of the silica tube was not measured directly, the assumption was made that it tended to remain at some relatively stable level in relation to the temperature of the vacuum chamber which surrounded it. Some indication of the validity of this assumption can be obtained from an auxiliary set of measurements made on a brass tube of identical size and construction as the fused silica tubes from which the formal determination was made.

The brass tube was subjected to an identical set of alternating length measurements and free-fall measure- ments as were the fused-silica tubes. The set of experiments with the brass tube followed immediately upon the conclusion of the determinations with the four silica tubes. The decision was made at the outset that regardless of what result was obtained with the brass tube, the result would not be included in the value of gravity to be reported.

The length intervals for the brass tube were measured at vacuum chamber temperatures ranging from 21.88 to $22.00{ }^{\circ} \mathrm{C}$ and corrected to $22{ }^{\circ} \mathrm{C}$ using a coefficient of thermal expansion of $18.5 \times 10^{-6}$ per degree

\begin{tabular}{|c|c|c|}
\hline \multirow{2}{*}{ Date } & \multicolumn{2}{|c|}{ Measured lengths at $22^{\circ} \mathrm{C}$} \\
\hline & $L_{2}$ & $L_{1}$ \\
\hline & Meter & Meter \\
\hline July 2,1965 & 0.99973306 & 0.29996206 \\
\hline July 7 & 73423 & 96230 \\
\hline July 12 & 73450 & $962 \quad 18$ \\
\hline July 14 & $734 \quad 34$ & 96194 \\
\hline July 16 & 73416 & 96202 \\
\hline
\end{tabular}
Celsius. The results are given in table 5 .

TABLE 5. Measured length intervals for brass tube

Brass has a temperature coefficient such that a change of $0.1^{\circ} \mathrm{C}$ would change the $1-m$ length by nearly $2 \mu \mathrm{m}$. The table indicates that, aside from a single shift between the first two measurements of the 1-m interval, the brass tube showed as good repeatability as the fused silica tubes. Since the temperature coefficient of thermal expansion of brass is about 27 times that of fused silica, the evidence appears to substantiate the assumption that the temperature of the falling object followed that of the vacuum chamber reasonably well.

\subsection{Uncertainty in the Final Result}

From the foregoing discussion of systematic error it is concluded that the principal known source of error of a systematic nature lies in the uncertainty in the value of the length standard. The uncertainty in the time standard is too small to affect the final result significantly.

Effects such as seismic disturbances, lunar and solar tides and random errors in the time and length measurements are included in the variability of the gravity values shown in tables 3 and 4 . The uncertainty in the final result is considered to be due principally to the contributions of this variability and the uncertainty in the evaluation of the invar length standard.

From the standard deviations of $0.00021 \mathrm{~cm} / \mathrm{s}^{2}$ for the length and time measurements and of $0.00039 \mathrm{~cm} / \mathrm{s}^{2}$ for the length standard, it is estimated that the uncertainly in the final result is represented by a standard deviation of $0.00045 \mathrm{~cm} / \mathrm{s}^{2}$.

\section{Comparison with Other Gravity Values}

The mean value of $980.1011 \mathrm{~cm} / \mathrm{s}^{2}$ given in table 4 is that determined directly from the measured parameters of the experiment. Since there is a gravity 
gradient of approximately $0.0003 \mathrm{~cm} / \mathrm{s}^{2} / \mathrm{m}$, it is necessary to know the effective height at which the machine determines the value. An expression has been derived by Preston-Thomas et al. [10] by which the effective elevation above the optical axis at which gravity is determined can be computed. The effective height, $H$, can be expressed as:

$$
H=H_{0}-g\left[\frac{1}{12}\left(\frac{t_{2}^{3}-t_{1}^{3}}{t_{2}-t_{1}}\right)+\frac{\Delta t}{6}\left(2 t_{2}+2 t_{1}+3 \Delta t\right)\right]
$$

where $H_{0}=$ elevation of the center of gravity of the silica tube above the optical axis at the time of release,

$\Delta t=$ time from the instant of release to the instant of initiation of the time measurements,

$t_{2}=$ time for the 1-meter interval,

$t_{1}=$ time for the $30-\mathrm{cm}$ interval.

In the apparatus $H_{0}$ had the value $56.8 \mathrm{~cm}, \Delta t$ was $0.1184 \mathrm{~s}$ and $t_{2}$ and $t_{2}$ were given typical values of 0.3486 and $0.1559 \mathrm{~s}$ respectively. The resulting value of the effective height above the optical axis is $14.2 \mathrm{~cm}$.

To establish a permanent reference point for the absolute value at a location suitable for gravity meter measurements, a location on the floor of the same room was selected as shown in figure 9. The absolute meas-

NORTH WALL OF BLDG.

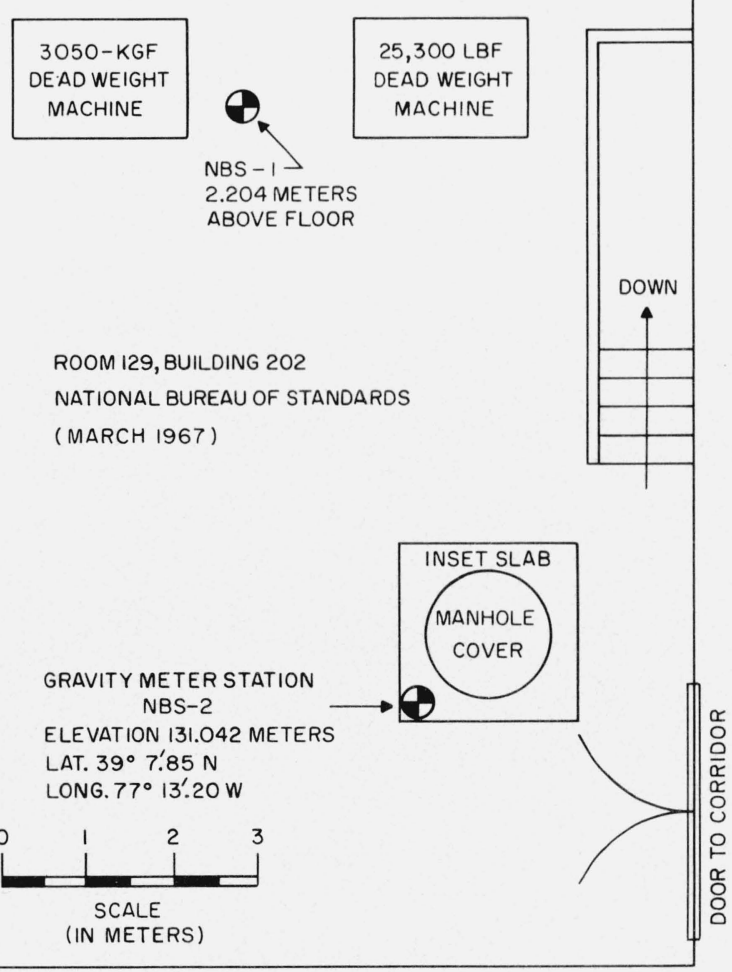

FigURE 9. Gravity reference station. urement site is designated NBS-1 and the reference site is designated NBS-2.

The elevation of NBS 2 was established by a first order survey by the Levelling Branch of the Coast and Geodetic Survey, Environmental Science Services Administration, U.S. Department of Commerce.

Gravity meter connections linking NBS-1 and NBS2 to the national gravity base in the Department of Commerce Building were made in November 1965 by the Gravity and Astronomy branch of the Coast and Geodetic Survey. These connections also included the station in the sub-subbasement of the East Building where Heyl's absolute measurement had been made.

A summary of the gravity differences taken from the report of the Coast and Geodetic Survey is given in table 6 . The differences are referred to the national gravity base, specifically the top of the east elevated pier in the gravity room of the Commerce Building. The gravity meter observations were made with three gravity meters in a double loop including two other stations in the area. The standard error for the stations NBS-1 and NBS-2 was $0.03 \mathrm{mGal}$ and that for the sub-subbasement of the East Building was 0.02 mGal.

TABLE 6. Gravity differences from national gravity base

\begin{tabular}{l|c}
\hline \multicolumn{1}{c|}{ Station description } & $\begin{array}{c}\text { Gravity value at the station minus gravity } \\
\text { value at the national gravity base in the } \\
\text { Department of Commerce Building }\end{array}$ \\
\hline $\begin{array}{l}\text { Support for optical axis of absolute gravity } \\
\text { machine, Station NBS-1 }\end{array}$ & -3.59 \\
$\begin{array}{l}\text { Permanent reference on floor of Room 129, } \\
\text { Bldg. 202, Station NBS-2 }\end{array}$ \\
$\begin{array}{l}\text { Floor of the sub-subbasement of the old } \\
\text { NBS East Bldg. }\end{array}$
\end{tabular}

The optical axis of the absolute gravity apparatus was $12.1 \mathrm{~cm}$ above the support plate which, in turn, was $220.4 \mathrm{~cm}$ above the floor. The machine, therefore, measured gravity at a point $232.5+14.2 \mathrm{~cm}$ above the floor. An adjustment of $+0.0007 \mathrm{~cm} / \mathrm{s}^{2}$ based on the observed gravity gradient of $-0.28 \mathrm{mGal} / \mathrm{m}$ of elevation was applied to the absolute result to correct it to station NBS-2. The absolute value of gravity for station NBS-2, as determined by the experiment, and the coordinates of NBS -2 are:

$$
\begin{aligned}
g & =980.1018 \mathrm{~cm} / \mathrm{s}^{2}, \\
\mathrm{Lat} & =39^{\circ} 07.85^{\prime} \text { north, } \\
\text { Long } & =77^{\circ} 13.20^{\prime} \text { west, }
\end{aligned}
$$

Elevation $=131.042 \mathrm{~m}$ above mean sea level.

A comparison to the Potsdam system may be made from the gravity meter connections to the national gravity base in the Department of Commerce Building. If a Potsdam value of $980.1180 \mathrm{~cm} / \mathrm{s}^{2}$ is assigned to that station, the corresponding value for NBS-2 would be $980.1150 \mathrm{~cm} / \mathrm{s}^{2}$. The NBS absolute result is $13.2 \mathrm{mGal}$ less than this. This result is in general agreement with the results of other recent absolute gravity measurements. 


\section{Conclusion}

A measurement of the absolute value of the acceleration due to gravity has been made and referenced to a permanent gravity meter station on the grounds of the National Bureau of Standards near Gaithersburg, Maryland. The value established for the reference station is $980.1018 \mathrm{~cm} / \mathrm{s}^{2}$ with a standard deviation of $0.0005 \mathrm{~cm} / \mathrm{s}^{2}$. This result, transferred to the top of the east elevated pier in the gravity room of the Department of Commerce Building, Washington, D.C., gives a value of $980.1048 \mathrm{~cm} / \mathrm{s}^{2}$ with the same standard deviation.

The author is deeply indebted for the helpful advice and assistance given by the staff of the National Bureau of Standards during the course of the work. $\mathrm{He}$ is particularly indebted to Mr. J. H. Troxell, who made the length measurements during the final determination.

\section{References}

[1] P. G. Roll, R. Krotkov, and R. H. Dicke, The equivalence of inertial and passive gravitational mass, Ann. Phys., 26, 442-517 (1964).

[2] A. H. Cook, The absolute determination of the acceleration due to gravity, Metrologia, 1, 84-114 (1965).

[3] F. Kühnen and P. Furtwängler, Bestimmung der absoluten Grïsze der Schwerkraft zu Potsdam (Veröffentlichung des K. Preuszischen geodätischen Institutes, N. F. no. 27) Berlin: P. Stankiewicz, 1906.
[4] P. R. Heyl and G. S. Cook, The value of gravity at Washington, J. Res. NBS 17, 805-39 (1936)RP946.

[5] J. S. Clark, An absolute determination of the acceleration due to gravity, Phil. Trans. Roy. Soc. London, Ser. A., 238, 65-123 (1939).

[6] H. L. Dryden, A reexamination of the Potsdam absolute determination of gravity, J. Res. NBS, 29, 303-14 (1942)RP1502.

[7] H. Jeffreys, On the absolute measurement of gravity, Monthly Notices Roy. Astron. Soc., Geophysical Suppls., 5, 398-408 (1949).

[8] P. N. Agaletskii and K. N. Egorov, Rezul'taty absoliutnykh opredelenii uskoreniia sily tiazhesti v punkte VNIIM (Leningrad), Izmeritel Tekhn., Vol. for 1956. no. 6, 29-34.

[9] A. I. Martsiniak, "Opredelenie absoliutnoi velichiny uskorenirâ sily tiazhesti po padeniiu zhezla $\mathrm{v}$ vakuume," Izmeritel Tekhn. Vol. for 1956, no. 5, 11-15.

[10] H. Preston-Thomas and others, An absolute measurement of the acceleration due to gravity at Ottawa, Can. J. Phys. 38 , 824-52 (1960).

[11] Å. Thulin, Une détermination absolue de $g$ au pavillon de Breteuil, par la méthode de la chute d'une règle divisée, Ann. Géophys. 16, 105-27 (1960).

[12] J. E. Faller, An Absolute Interferometric Determination of the Acceleration of Gravity. Thesis, Princeton University, 1963.

[13] A. H. Cook, A new absolute determination of the acceleration due to gravity at the National Physical Laboratory, England, Phil. Trans. Roy. Soc. London, Ser. A., 261, 211-252 (1967).

[14] C. Volet, L'intensité de la pesanteur déterminée par l'observation de la chute d'un corps, Comptes rendus de l'Académie des sciences, 224, 1815-16 (1947).

[15] A. Sakuma, Etat actuel de la nouvelle détermination absolue de la pesanteur au Bureau international des poids et mesures, International Association of Geodesy, Bulletin géodésique, n.s., no. 69, 249-60 (1. sept. 1963).

[16] A. H. Cook, Recent developments in the absolute measurement of gravity, International Association of Geodesy, Bulletin géodésique, n.s. no. 44, 34-59 (1. juin 1957).

(Paper 72C1-264) 